\title{
THE IMPACT OF PLACE-BASED PEDAGOGY ON TEACHERS' PROFESSIONAL IDENTITIES, INSTRUCTIONAL DECISIONS, AND COLLABORATIONS
}

A Dissertation
presented to
the Faculty of the Graduate School
at the University of Missouri-Columbia
In Partial Fulfillment
of the Requirements for the Degree
Doctor of Philosophy

by

JULIE SHEERMAN

Dr. Amy Lannin, Dissertation Supervisor

JULY 2020 
The undersigned, appointed by the dean of the Graduate School, have examined the dissertation entitled

\section{THE IMPACT OF PLACE-BASED PEDAGOGY ON TEACHERS' PROFESSIONAL IDENTITIES, INSTRUCTIONAL DECISIONS, AND COLLABORATIONS}

presented by Julie Sheerman,

a candidate for the degree of Doctor of Philosophy,

and hereby certify that, in their opinion, it is worthy of acceptance.

Professor Amy Lannin

Professor Jill Ostrow

Professor Lori Wilcox

Professor Angie Zapata 


\section{Acknowledgements}

I thank my committee members, who provided time and direction during the process. Dr. Jill Ostrow, I am awed by your ability to provide such quick and clear feedback. Dr. Lori Wilcox, your versatile career has taken many turns and left you broadly versed in all elements of research and oversight. You were a trusted sounding board throughout. Dr. Angie Zapata, you are an amazing teacher. I know no one else with your uncanny ability to prompt the reading of entire books with one quick comment, but I did experience this firsthand.

Cheerleaders included Dr. Christy Goldsmith, Dr. Lara Dieckmann, and Dr. Marty Hawkins. Marty, your investment of time and wisdom is the reason this project saw an end point, and I cannot thank you enough.

For the teachers who willingly took a place-inspired journey with me, I owe you so much. Without your flexibility and wisdom, we would all be sitting in square classrooms reading textbooks. I can't mention you by name but you were the biggest part of this work.

To Dr. Amy Lannin, who chaired my committee, you are a model of kindness and thoughtfulness. We have managed a lot in the last few years, including this. I admire you for always doing the right thing, even when it leads to weighty work.

Mom and Joyce, thank you for always asking but never pushing. I appreciate you for so many reasons, including your support during this process. Cathie, I thank you for being the model of all that a thinker should be. In forty-seven years, this little sister has not stumped you once. For Kaye, thank you for always asking the right questions and making them seem like my idea. When I think of the importance of place, I think of 
you.

For John, Emma and Tess, thanks for being the reason I wanted to leave this desk.

When I close my eyes, I see each of you encouraging my work on this project, and I humbly thank you. 


\section{Table of Contents}

Acknowledgements $\quad$ ii

List of Figures $\quad$ vii

List of Tables $\quad$ viii

$\begin{array}{ll}\text { Abstract } & \text { ix }\end{array}$

Chapter 1: Introduction to the Study 1

$\begin{array}{ll}\text { Chapter 2: A Review of the Literature } & 7\end{array}$

$\begin{array}{lr}\text { Theoretical Perspective } & 8\end{array}$

Literature Review 11

$\begin{array}{ll}\text { Defining Place in Learning } & 12\end{array}$

Place-Based Pedagogy 13

The Spectrum of Place-Based Pedagogy 16

Defining Qualities of Place-Based Pedagogy 19

Disciplinary Literacy Aids Problem Solving 23

Enacting Place-Based Pedagogy through Professional Collaboration 26

Qualities of Effective Ongoing Professional Development 27

Influential Studies Concerning Effective Place-Based Professional Development 27

The Gap in the Literature $\quad 29$

Broadening Current Place-Based Models Through Professional Development 31

$\begin{array}{ll}\text { Closing Discussion } & 31\end{array}$

$\begin{array}{ll}\text { Chapter 3: Methods } & 34\end{array}$

$\begin{array}{ll}\text { Methodology } & 34\end{array}$

$\begin{array}{ll}\text { Details of This Study } & 37\end{array}$ 
$\begin{array}{lr}\text { Problem Statement } & 39\end{array}$

Timeline of the Study $\quad 40$

$\begin{array}{ll}\text { Participants } & 41\end{array}$

Research Setting - The "Place” of the Work 44

Researcher Positioning $\quad 45$

Data Collection $\quad 45$

$\begin{array}{lr}\text { Data Analysis } & 50\end{array}$

Limitations of Research $\quad 5$

Limitations of Implementation $\quad 5$

$\begin{array}{lr}\text { Ethics } & 54\end{array}$

$\begin{array}{lr}\text { Potential Benefits } & 54\end{array}$

$\begin{array}{lr}\text { Chapter 4: Findings } & 56\end{array}$

$\begin{array}{lr}\text { Overview of Data Analysis Procedures } & 57\end{array}$

Overview of the People and Places in the Study 57

Description of PD Program at Center of Study 59

$\begin{array}{lr}\text { Findings } & 60\end{array}$

Sense of Place is Integral to Sense of Self, Becoming Part of Personal and Professional Identity 61

Sense of Place Connects to Teachers' Expertise in Guiding Classroom Decisions 69

Sense of Place, Supported by Inquiry-Mindedness, Builds Respectful Professional Relationships 72

Sense of Place has Led to Deep and Enduring Professional Growth in Teachers 81

$\begin{array}{lr}\text { Conclusion } & 90\end{array}$

$\begin{array}{lr}\text { Chapter } 5 & 94\end{array}$

$\begin{array}{lr}\text { Summary of Findings } & 95\end{array}$

Sense of Place is Integral to Sense of Self, Becoming Part of Personal and Professional Identity 95

Sense of Place Connects to Teachers' Expertise in Guiding Classroom Decisions 95

Sense of Place, Supported by Inquiry-Mindedness, Builds Respectful Professional Relationships 96 
Start Small

Build Partnerships In and Out of School

Fuse Place-Based Pedagogical Practices with Existing Instruction/Curriculum 


\section{List of Figures}

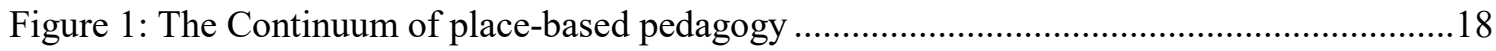

Figure 2: Photograph of highway patrolman presenting to kindergarten class...........................77

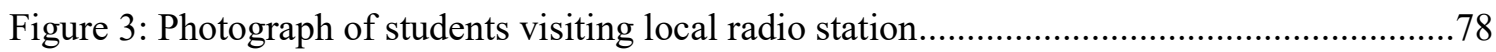

Figure 4: Sample lesson slide used as part of a lecture on water quality tests.............................86

Figure 5: Revised lesson materials showing mapping and sketchnoting ....................................87

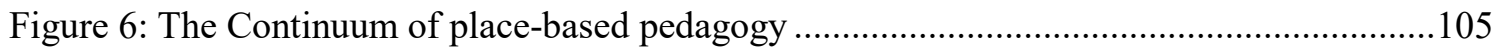




\section{List of Tables}

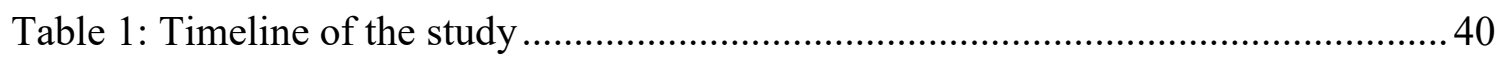

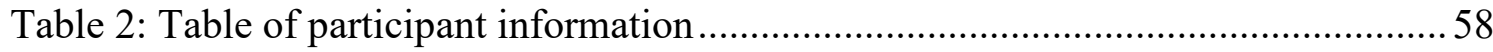




\begin{abstract}
This design study uses a design-based, formative approach to consider teachers' understanding and use of place-based pedagogical practices. The study focuses on teachers' awareness, understanding and use of place as they implemented classroom instruction and built a professional development experience for colleagues. The research spans three months as the team of six teachers (colleagues at a local district) planned, implemented, and reflected on place-based pedagogical shifts. At the heart of the research is the question of how a place-based instructional perspective impacts teaching and professional growth. Ultimately, findings suggest that this group, both collectively and individually, has come to value place as it affects meaningful understanding. Not satisfied with strictly textbook-driven instruction, this team has developed ways to expand school walls, create meaningful experiences for educational colleagues and secure community partnerships valuable to all aspects of this professional growth. These teachers believe that understandings of the importance of place will transcend course titles and school boundaries in order to actively engage learners.
\end{abstract}




\section{Chapter 1: Introduction to the Study}

"People divorced from community, occupation, and association are first and foremost among the supporters of extremism."

\section{— Robert D. Putnam, Bowling Alone: The Collapse and Revival of American Community}

Driving through a freshly cut hay field in the back of a flatbed farm truck, a group of six rural educators is joined by regional experts representing a range of professional backgrounds. The teachers in the group instruct different ages, spanning elementary to high school, and specialize in varied content areas including social studies, science, and English language arts. They are linked by a common interest in place-based instruction and professional collaboration. Along for the ride are area Department of Conservation specialists whose expertise of indigenous plantings led to a 60-acre, five-tier Farm Renewal Project aimed at saving soil and limiting erosion on farm acreage peripheral to the main pastures. Add to the list one local historian, who also owns the town's antique store, serves as Chamber of Commerce secretary, and resides on a Century Farm as a fourth-generation occupant. Rounding out the group is the Executive Director of the local Museum at the center of this study, with personal ties to the area's favored son. As this professionally diverse group tours the land with local teachers, field experts (e.g., conservation agents and local historians) share perspective on the value of the place, including historic, agricultural, and social worth, while teachers consider how an emphasis on place has the potential to enrich classroom curriculum.

The setting is a Century Farm in north central Missouri where members of the planning team for the Here \& Now! Place-Based Workshop gather to craft a professional learning experience. Through experiential learning opportunities, these educators consider how the content they teach--whether biology, geography, or regional literature-- 
ties to a sense of purpose and place. As lively discussions arise, the group seems "tuned in," yet at some point there must be a stepping back to consider the measurable value of the work. From this beginning, we discussed questions and ideas about the work: Does it meet educational objectives prioritized by the district and state? Can it translate to strengthen classroom instruction? Will educators with a deeper understanding of place be more mindful as they plan and implement instruction? Will regular, in-depth professional collaboration result from the endeavor? To create an excursion-filled workshop while building community "seems" valuable, but can this use of time and resources be justified? These questions, along with personal and professional experiences, helped shape this research study.

For this group, conversations surrounding place-based pedagogy are not new. Upon their return from a National Writing Project-hosted design workshop in Philadelphia in the spring of 2017, the local effort to link the school and museum through a formalized partnership prompted the group to form the Museum Education Advisory Board and one offshoot: The Museum Education Planning Team, made up of the team interviewed for this project. The Museum Education Advisory Board, comprised of local field experts and educators with an interest in place-based pedagogy, has now been in place for three years. They serve to help guide program planning and also connect with community partners and report back to the Advisory Board each quarter.

The Museum Education Advisory Board has, since the spring of 2017, held annual meetings to steer the direction of educational programming at the museum, including the Museum Here \& Now! Place-Based Workshop. As the Museum Education Planning Team has developed through professional readings, collaboration and reflection, 
they have considered how an understanding of place-based pedagogy can best impact other educators.

Amid the pedagogical challenges and priorities of place-based instruction is the complexity of understanding the very idea of place. More than its recorded history and geography are the complex situations and relationships that have defined an area since before the existing community took root. While some place-based pedagogy has celebrated community by drawing on nostalgic memory, richer instructional models interrogate place more honestly by questioning current and historic power structures (Demarest, 2015; Donehower et al., 2007).

This realistic look at social, political, and material issues can allow educators “...to initiate a broader dialogue...about the geographic, economic, social, and cultural boundaries" (Clifton, 2017, p. 192). Place-based teaching accepts a critical stance in order to develop “...more robust understandings of a complex situation” (Clifton, 2017, p. 77). Teachers willing to engage in this work value the critical thinking that pedagogy promotes surrounding issues of place. They believe that place-minded people better engage with their communities to promote thoughtful understanding.

This is a particularly salient issue for rural areas, where the school often serves as the heart of the local community. Steeped in their own complex history, schools play an important role in developing a broader understanding of the community. There has been a shift from the early days of public education when local needs guided pedagogical practice, i.e., an emphasis on agriculture in rural schools (Brooke, 2003; Demarest, 2015; Dewey, 1938). The current climate of public education emphasizes uniformity as, understandably, teachers adopt a defensive posture to maintain their status as "highly 
qualified." Some feel on guard to defend their curricular choices and teaching styles while those in positions of authority, albeit well intentioned, dictate what and how they teach. As the struggle continues to improve the "achievement" of students, schools spend significant money on programs and materials designed by textbook companies to provide teachers with the tools needed for effective instruction. The educational system's intentions of providing "ready-to-use" materials often do not line up with desired local classroom results.

Could it be that schools are missing an obvious approach? Rather than promoting uniform, one-size-fits-all learning experiences void of personal engagement, perhaps educational environments should grant teachers other options, specifically more freedom to consider the uniqueness of local place and community when planning instruction.

Place-based teaching, which values the impact that local community has on understanding and engagement, can address issues teachers face in classrooms. Replacing a generic, textbook-driven instructional approach, place-based teaching models start by considering the immediate environment and what is familiar and knowable through firsthand observation and experience. This localized, place-based approach leads to enhanced engagement which then spirals outward to broader circles of understanding.

Given the necessity to contextualize instruction, this research uses a design study approach to explore the growth in a team of teachers committed to understanding and implementing place-based instructional methods. Grounded in the work of Reinking and Bradley (2008), the design study approach values a blend of theory and practice. Rather than focusing solely on theory, the design study approach considers the practical workability born out of a given theory. Design studies, according to Reinking and 
Bradley (2008) “....are not aimed only at creating conditions that allow an intervention to accomplish a pedagogical goal" (p. 19). Design studies also value the theoretical underpinnings which guide the researcher's practice. In short, design studies blend the theoretical and practical understanding surrounding instructional changes. The design study approach is especially relevant for place-based pedagogy because of its emphasis on research-based practice.

Guided by a sense of place, this team of teachers considers place-based pedagogy both in their classrooms and as they collaboratively design a professional development experience for other educators. Possessing a range of professional experience, the team of six uses a place-based, collaborative approach. Their varied teaching expertise spans content area, grade level, and years in the classroom. Data collection for this study spanned three months as these teachers planned, implemented, and reflected on placebased pedagogical shifts. Since 2017, the team had participated as part of a leadership team guiding the development of a professional development model, so their insights refer back to a time prior to the start of the study. Like other design studies, this one takes a practical, adaptive approach to think through place-based instruction. At the heart of the research is the question of how a place-based instructional perspective impacts teaching and learning.

As the group engages in place-based work, they are fueled by an enthusiasm about the potential for meaningful learning. Not satisfied with textbook-driven instruction, they innovate ways to expand school walls and secure community partnerships. This inquiry-driven approach, they hope, will result in learners whose understandings will transcend course titles and school walls, and instead build thoughtful 
citizens motivated to contribute to the common good. As Museum Executive Director Kaye Malins noted at the outset of the work:

In all the years of working to build the museum, it was the school partnership that had taken a back seat to what seemed more pressing matters like curation and fundraising. I'm so comforted by the fact that this endeavor fills a longstanding need to join two partners integral to the town and its future: the school and the museum. (Personal Communication, October 12, 2020) 


\section{Chapter 2: A Review of the Literature}

The purpose of this design study is to examine professional growth in a team of teachers committed to exploring place-based instruction. This chapter discusses the theoretical perspectives guiding this study and frames place-based pedagogy according to its foundational qualities. It reviews relevant literature concerning aspects of place-based pedagogy, including its characteristics as collaborative, inquiry driven, and disciplinaryliteracy centered.

Place-based learning has been largely studied in content-specific ways. Some view place-based learning as synonymous with outdoor education, having its roots in physical education (Tan \& Atencio, 2018). Others see place-based learning as tied to physical landscape in an effort to improve science instruction. Perhaps predating the use of place-based pedagogy in both science and physical education is its value for social studies teachers, who have long used the experiential qualities of "field trips" to bring historic spaces to life for students (Percoco, 2017). Ultimately, place-based learning is more than taking students outside the classroom. It relies on using the context of people and places to drive engagement and learning.

While place-based pedagogy can be meaningful to physical education, social studies and science teachers, the movement's true potential lies in an underutilized interdisciplinary approach. Although a considerable number of studies have explored potential benefits of place-based learning, recent research has undertaken the task of exploring place-based pedagogy as collaborative and interdisciplinary, thereby uncovering the unique richness of the instructional approach. This study investigates the largely overlooked potential that place-based professional development, distinctly 
interdisciplinary and collaborative in nature, has for educational environments.

\section{Theoretical Perspective}

I approach this study from a sociocultural perspective, and a constructivist paradigm, as my thinking aligns with the view that social interaction and environment have a profound effect on learning. The focus of place-based teaching is grounded in sociocultural theories of learning as first identified by Vygotsky (Vygotsky, 1986). Of particular relevance is his work analyzing the interaction between words and meaningmaking to support the view that language is meant to be social rather than merely internal.

A central tenet of sociocultural perspective is that personal identity is heavily influenced by social factors (i.e., community). This means that "self" is constructed collectively, rather than just internally (Leavy, 2017; Gee, 2004). According to this theory, meaning exists in context, and actions cannot be separated from the environment. Language development and learning in general occur as meaning results from human interaction with one's surroundings (including both place and people). Because social exchange underscores cognitive development, "all the higher functions originate as actual relationships between individuals" (Vygotsky, 1986, p. 57).

As this theory pertains to schooling, Vygotsky emphasizes that students and adults share ownership in learning. Since constructivism highlights the role of social interaction in development and learning, the relationship formed through teacher-learner interaction is a key component of identity development. As learners create new knowledge structures, they continually assimilate emerging insight with existing beliefs. Knowledge, then, is based on the constant recreation of meaning as learners seek expanded understanding (Vygotsky, 1986; Freire, 1983; Foucault, 1978). 
It follows that sociocultural theorists emphasize the importance of learning in the community and the home. Student identity includes the identity they form in and out of school. Individual understanding and accomplishment, then, cannot be understood apart from society and culture (Lewis et al., 2007; Heath, 1983). Teacher and student engagement, happening at the immediate, localized level, is integral to deeper learning. Effective schooling happens in the context of the community, and not separate from it, as students learn to read, write, speak, and think (Moffett, 1983; Moffett, 1988). Whether by design or chance, "experiential realities," including sensory experiences, guide learners in their development (Freire, 1983). Current theorists continue to build on Vygotsky's foundational theory highlighting the importance of community-centered schools. Placebased pedagogy grounds itself in the view that school cannot effectively function separate from community (Fang, 2012; Lesley, 2014).

Gee (2004) furthers the work of Vygotsky by extending theoretical linguistics into the realm of education, keeping at the forefront "how language and learning work at school and in society at large" (p. 3). Driven by a desire to understand how schools (in particular their "specialist varieties of language") can alienate learners, Gee advances sociocultural theory by considering the various language demands of academic contexts. Gee's (2004) central argument asserts that “...people learn new ways with words, in or out of school, only when they find the worlds to which these words apply compelling" (p. 3). Gee (2004) highlights that longstanding practices in public schools often disengage and alienate students while privileging those from homes of higher socio-economic status (p. 3). In academic subjects, such as biology and social studies, academic language is tied to technical ways of thinking. It follows, then, that children from wealthier homes 
"...often get an important head start before school at home on the acquisition of such academic varieties of language" (Gee, 2004, p. 3). This trend results from environmental factors, such as spoken language and exposure to printed language, that more closely align with academic language.

By tying learning to place, Gee argues, children learn by sharing tangible experience. Place-based learning promotes equity, since all students, regardless of their access to resources, can pull from the immediate environment to make meaning and build connections to new knowledge. The immersive nature of place-based learning is accessible to all children, and a source from which shared understanding can build.

In chorus with Vygotsky, Gee emphasizes the social nature of learning. Gee (2004) likens literacy development to gaming, noting that “...people 'play' in a domain in such a way that they can give situation-specific meanings to the styles of language associated with that domain" (p. 51). This view of literacy, the idea that "...learning to read is a cultural and not primarily an instructed process" underscores the potential that placebased pedagogy has for education (Gee, 2004, p. 13). His views build upon Street's (1984) ethnographic research, highlighting that “...pre-existing social formations in a particular place could serve as important receptors oreven catalysts for literacy development...” (p. 22). General agreement in the literature supports the notion that sense making is an inherently social activity.

In all, the sociocultural view of language sees literacy development as “...a delicate interplay of social, cultural, economic, political, and even geographic forces" (Brandt \& Clinton, 2002, p. 340). Context drives learning and literacy development in a complex blend of situational factors. Place-based pedagogy draws upon the immediate 
environment to offer relevance, grounding learning in practical application of concepts.

As instructors attempt to explore place-based pedagogy, these underlying theoretical concepts reinforce that education professionals, like all learners, can benefit by relying on context to drive understanding. Teachers adopting a place-based stance plan instruction knowing that deep, enduring understanding stems from instruction rooted in the context of everyday experience (Fang, 2012; Lesley, 2014; Moffett, 1988; Street, 1984).

\section{Literature Review}

This literature review discusses place-based instruction and explores the approach's key characteristics. Following a definition of place, an opening section includes the rationale and history behind this pedagogical approach. Place-based pedagogy serves as the foundation upon which this design study rests as it explores the impact that place-based awareness has on teachers. The literature review then situates place-based pedagogy according to three of its key qualities, grounding it as collaborative, inquiry driven, and disciplinary-literacy centered. Together these characteristics of place-based pedagogy emphasize the importance of a critical stance that leads learners to question and challenge historic and current realities.

In addition to the verifiable physical realities that can be observed and proven (e.g., water and air quality trends over time) are the social patterns less easily understood. Freire (1998) suggests that "students--of any age--should be taught to 'read the world' in order to see the inequities and opportunity around them" (p. 36). As he worked in Brazil to teach citizens to read, he also taught them to question the reasons for oppression. It is through Freire's work that the idea of "place as text" originates. To him, "sense of place" 
extends beyond mere awareness into taking responsible action (Freire, 1998).

The review of research emphasizes that place-based instruction requires collaboration, specifically the working together of multiple stakeholders including students, teachers, and community members. Place-based instruction requires that teachers adapt to changing circumstances. Drawing on rich disciplinary expertise, teachers constantly collaborate with colleagues and community to facilitate learnerdriven inquiry. Rather than prescriptive curriculum, place-based instruction relies on questions to guide learning. Its deeply contextualized nature tethers place-based learning to sociocultural theory.

\section{Defining Place in Learning}

Before meaningful discussion of place-based pedagogy can occur, it is first necessary to establish a clear understanding of the term "place." As defined by Semken, et al. (2017), place encompasses “....any locality that becomes imbued with meaning through human experience" (p. 543). Socially constructed, places include the coexistence of cultural and physical landscapes, “...formed of interactions between people and the physical environment” (p. 542). Values attached to place include aesthetic, economic, recreational, spiritual, familial, cultural, historical, political, and scientific (Austin, 2015; Brooke, 2003; Demarest, 2011; Gruenewald, 2003; Oncescu \& Giles, 2014; Sobel, 2013; Stack, 2016).

Beck (2005) explains how possessing a strong sense of place can impact learning, since the "...strong engagement with and discussion of subject matter that is deeply relevant to students' lives beyond the classroom" allows people to function more thoughtfully in all walks of life (p. 393). Deep understanding of and connection to place 
provides the framework for "reading" and understanding "...the word and the world" (Perry, 2012, p. 60) as learning becomes contextualized through complex understandings of place.

\section{Place-Based Pedagogy}

Building on this deep regard for one's surroundings, place-based instruction grounds learning in what is known through experience and observation. By pursuing local questions, critiquing local truths, developing local partnerships with individuals and organizations, and studying in local surroundings, learners develop deeper understandings that promote their growth as students and thoughtful citizens (Smith, 2002). Teachers lead this shift from typical, content-focused learning to viewing students as active participants in local democracy (Clifton, 2017). They guide students in their evolution as learners who are increasingly able to call upon content knowledge in addressing issues-based questions, rather than teaching discrete academic concepts in checklist fashion hoping the knowledge proves useful in some distant context.

Place-based learning is not a new concept. Defined by Semken et. al (2017) as “...a comparatively modern modality with ancient roots," the locally situated and environmentally informed pedagogy aims to “...foster better understanding of, and hence more informed and sustainable dwelling in, one's surrounding landscapes, environments, and communities" (p. 542). Because place-based learning draws on what is familiar to students, it adds local context to concepts and practices that could otherwise appear abstract and irrelevant to students. In the early days of public schools, it was an intuitive design component (Dewey, 1966). School schedules revolved around the community calendar and local sustainability (e.g., through farming, hunting or mining). 
The Progressive Education Movement is rooted in the belief that individual diversity should be celebrated and that interest and motivation should drive learning. Progressives believe that all people should be schooled to take an active and critical stance in community affairs in order to participate in democracy (Bode, 1938; Dewey, 1938; Pratt et al., 1948; Washburne, 1952). According to this model, education was "...attentive to the growth of the child, widening interests, and self-direction of activity" (Stack, 2016, p. 9). To Progressives, "traditional schooling" emphasized obedience, uniformity and passive listening above critique and reflection. These foundational principles of self-direction and community-mindedness a crucial shift, contrasting with traditional education it deemed "...remote, disconnected from life, and characterized by piecemeal learning, competition over cooperation, repetition, unfamiliarity, regimentation, and drill" (Stack, 2016, p. 17). Current discussions of place-based learning acknowledge the movement's alignment with Progressive goals. Today's education system faces many of the problems first widely discussed as the Progressive Movement was gaining popularity (Austin, 2015; Brooke, 2003; Demarest, 2011; Donehower et al., 2007).

As society began to value uniformity and abstract "marketable" skills detached from a unique sense of community, schools shifted further away from place-based principles like self- direction and collaboration. Though educators have for a few decades studied a return to place-based learning and its potential to enhance community, the push has not permeated the majority of schools (Demarest, 2011; Gruenewald, 2003).

From daily structural realities (e.g., the bell system signaling a move from class to class and the physical walls separating classrooms) to teacher preparation programs (i.e., 
teacher certification courses emphasizing knowledge in individual subject areas), prevalent secondary school structures value distinct content knowledge over real-world application (Buehl, 2011). Teachers need support as they transition professionally, returning to a world in which schools are part of the democratic public sphere with teachers serving as public intellectuals responsible for guiding students as informed and critically engaged citizens (Jacobs, 2011; Donehower et al., 2007; Clifton, 2017). While teachers' content expertise is integral in the place-based model, it becomes part of the bigger whole rather than the sole focus.

A place-based approach challenges students to take ownership of their learning in ways not always supported in school (Austin, 2015; Brooke, 2003; Deringer, 2017; Sobel, 2013). Teachers guide students to understand that meaningful learning extends beyond the classroom and is rooted in a strong sense of place, both historic and current. As students come to understand the environment, and to better question what they do not understand, they can ask meaningful questions to explore themselves and their sense of belonging while also critically considering the people and systems around them (Barley \& Beesley, 2007; Demarest, 2015; Smith, 2016).

Advocates of place-based teaching believe that people tied to their community contribute more meaningfully (as compared to students focused on acquiring skills and knowledge in order to "move on"). Place-based educational environments put learners in the center, rooted in the context, rather than standing outside looking in as often happens in school settings where passive textbook study is the accepted norm. When schools ignore the integral connection between place and learning, students can lose the opportunity to make connections and generalize beyond an individual unit of study 
(Austin, 2015; Brooke, 2003; Oncescu \& Giles, 2014; Sobel, 2013). Demarest (2015) reminds us that “...students learn from the total school experience, not just what happens...in class" (p. 15). She offers the example of map making, an activity which allows students to layer interdisciplinary content into maps, including the history, geology, story/narrative, and animal habitat showcasing various aspects of place (p. 22). The ability to imagine ways that new learning applies in multiple contexts can aid students as they learn to generalize.

Though students' affiliation to place will shift upon leaving school due to forces within and beyond their control, place-based pedagogy provides transferable understanding. The engagement and ownership students experience through place-based inquiry will apply to new environments. Their community roles will evolve as they age. The groups with which they identify will shift. And yet the enduring habits of mind, including the ability to question, critique, and see multiple perspectives, will persist and transfer to new environments (i.e., communities) once students are guided using a placebased instructional model (Austin, 2015; Brooke, 2003; Demarest, 2015; Elliott \& Jacobs, 2011; Jaxon \& Salter, 2016; Lesh, 2011; Oncescu \& Giles, 2014; Sobel, 2013; and Smith, 2016). As Deringer (2017) notes, place-based learning “...is an opportunity for formal education to create a more humanizing and generative society through identifying injustices and promoting compassion at a local level” (p. 337).

\section{The Spectrum of Place-Based Pedagogy}

Though implementation can vary widely, a place-based teaching framework includes several anchoring principles common across implementation level. Semken et al. (2017) describe place-based learning as a continuum ranging from “...the simple use of a 
few local artifacts or resources...to a fully transdisciplinary curriculum in which place and its attributes define scope and sequence and are the primary loci of student inquiry" (p. 544). Effective place-based instruction requires that teachers facilitate active student engagement and ongoing reflection. Through immersive instructional activities, teachers foster a deep understanding of the local community from which broader understandings develop.

Place-based pedagogy can be implemented in varying degrees. It is possible for teachers to test out the approach with a single instructional plan spanning one class period before deciding if and how to implement more fully. The graph below shows the range of implementation. On the left is the experimental category of implementation for teachers without the experience, time or permission to fully take on this approach. New to the idea of place-based pedagogy, teachers in the experimental phase direct the work of contextualizing lessons according to place by engaging students in an activity that requires place-mindedness. On the right, under full implementation, are teachers who have undergone a pedagogical shift in order to maintain learning environments fully devoted to student-led inquiry. Here, teachers work in interdisciplinary teams to guide inquiries into local issues drawing on disciplinary expertise. In the sections below, these characteristics of full implementation are spelled out to describe the defining features of a place-based approach. 


\section{Figure 1}

Continuum of Place-Based Pedagogy

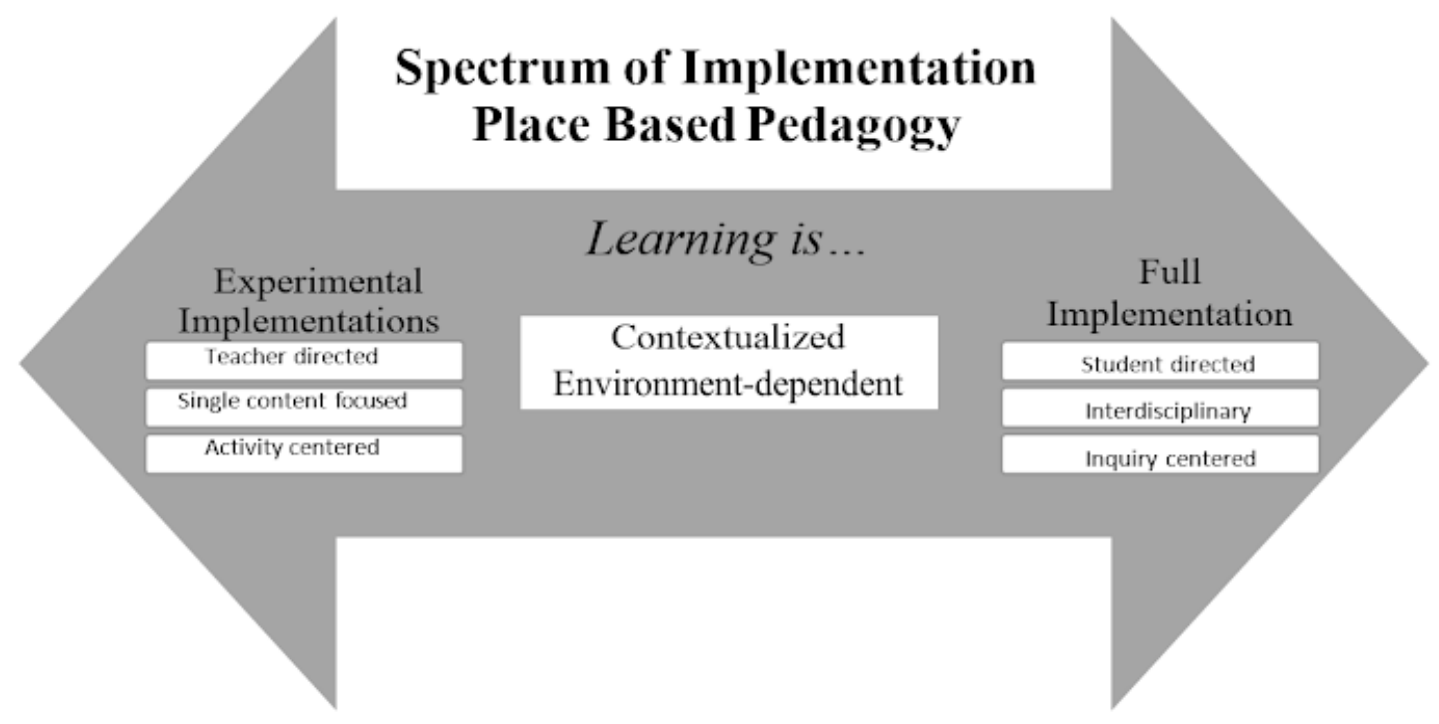

Teachers adopting a more comprehensive place-based approach believe that with a deep understanding of community comes an increased responsibility to participate in it. While many times this leads to celebration of key moments and local successes, heightened awareness also prepares students to adopt an informed, critical stance to question and resist certain traditions and policies, both formal and unwritten (Clifton, 2017). When it comes to the cultural life of a community, preservation and sustainability are not synonymous. It can be necessary for communities to let go of beliefs and practices that privilege certain members while overlooking, or even subverting, the views and values of others (Clifton, 2017; Deringer, 2017; Donehower et al., 2007). At times, educators and institutions resist this approach because of its potential to be "messy" and unpleasant (Dobbs, Ippolito, \& Charner-Laird, 2017). Inquiries might unearth difficult 
issues and unfavorable moments in local history. Clifton (2017) explores the ways in which students can analyze stakeholders and multiple perspectives in order to look at the complexities of tense situations. Beyond a two-sided or right/wrong approach, an inquirydriven, localized approach invites multiple perspectives and nuanced meaning. Placebased instruction requires a willingness to step into uncomfortable territory. To teachers adopting the approach, the risk is worthwhile.

Critically responsive people lead more fruitful, purposeful lives (UNESCO, 2005; Behrman, 2006; Ellis \& Eberly, 2015; Hill, 2014). As Beck (2005) defines it, this “...strong engagement with and discussion of subject matter that is deeply relevant to students' lives beyond the classroom" allows people to function in all walks of life (p. 393). The idea that students should actively contribute to learning by determining questions and exploring power relationships makes critical response a key part of the approach (Allen \& Alexander, 2013; Demarest, 2015; Percoco, 2017; Selwyn, 2010; Wilhelm \& Novak, 2011). Place-based learning environments regularly work into activities the practices of critical questioning, making these habits part of the classroom environment.

\section{Defining Qualities of Place-Based Pedagogy}

Place-based learning environments value relevance and familiar context, believing these factors lead to enduring understanding. To create and sustain a placebased educational culture requires an understanding of the overlapping main qualities of this kind of instruction. Place- minded teachers believe in collaboration among disciplinary experts to facilitate learning that is driven by questions. 


\section{Place-Based Pedagogy as Collaborative}

Educators planning place-based instruction should be prepared for collaboration that is both organic and messy. With the messiness, though, comes richer meaning than typical educational models promote (Demarest, 2015; Jetton \& Shanahan, 2012). Placebased teaching connects deepening content knowledge and disciplinary literacy skills (discussed later) to explore genuine questions. Thoughtfully designed place-based pedagogy has an interdisciplinary focus. More broadly than a single content area, this instruction invites the learner to consider authentic questions or problems. While content knowledge is integral to exploring the question, this knowledge is not sifted out as a discrete end goal. Rather, disciplinary skills are part of an integrated quest to explore an issue (Buehl, 2011; Demarest, 2015; Marcus et al., 2012).

Strong models of place-based instruction feature an interdisciplinary team of educators who draw upon unique features of community (including the physical, historical, social, cultural, and political environments). Rather than asking students to adopt temporary and discrete roles as students of history, geometry, literature, etc., placebased instructional models advocate for an integrated approach that teaches students as engaged and thoughtful citizens whose critical perspective can make an impactful difference now and in the future (Austin, 2015; Brooke, 2003; Demarest, 2015; Oncescu \& Giles, 2014; Sobel, 2013). In this program, an interdisciplinary team of adults lead the work, modeling inquiry-driven collaboration that relies on disciplinary skill.

\section{Place-based pedagogy as inquiry driven}

Inquiry is the ability to look at a text or situation and ask meaningful questions in the struggle to understand. Teachers foster an environment of inquiry when they guide 
students to appreciate multiple perspectives or truths and when they foster habits of mind that, over time, better prepare students for further academic study and real collaborative engagement. Hill (2014) suggests that inquiry means “...allowing students to explore solutions to their problem," thereby creating "...a classroom environment that is amenable to openness and student autonomy, which promotes student motivation, reading and academic achievement" (p. 451). Student questions drive learning activities in a pattern that organically breaks down artificial barriers between school and the "real world." As a result, students learn “...tools for dialogue and critical inquiry” in a setting that invites students and teachers to function as co-learners (Flower, 2008, p. 17). An environment of inquiry supports students in constructing meaning rather than constantly identifying someone else's notion of "correctness."

The cycle of inquiry includes generating questions, pursuing possible answers, engaging in reflection on new understandings, and taking action as a result of learning. The environment of inquiry becomes a mindset for the learning environment. Inquiry is not something that happens as a one-time experience. Instead, learners use the aforementioned inquiry processes to approach any learning situation. Students and teachers alike approach learning as a self-directed investigation, where outcomes are not predetermined and certainty is not the goal. Teachers, students and community partners support one another in the quest for new understanding.

In addition to facilitating the ability to read and write thoughtfully and critically, place-based instruction also requires that teachers lead students to develop the ability to question. When students construct meaning and understand someone else's perspective, the critical stance promotes cross-pollination of ideas. Instead of viewing content areas 
discreetly, each with its separate concepts and expectations, students are better able to see patterns across learning. As Hill (2014) notes, inquiry motivates students “...to read and write beyond the requirements of the school day," strengthening their literacy skills as a result (p. 458). The students and teacher work in collaborative ways, constantly defining and redefining their learning. Inquiry-driven pedagogy requires flexible, adaptive teachers able to continuously wrestle with unknowns (Dobbs et al., 2017).

\section{Place-Based Pedagogy as Disciplinary/Literacy Centered}

Place-based instruction draws upon disciplinary expertise, including both the deeply ingrained ways of thinking in the disciplines as well as discipline-unique ways of reading, writing and communicating. As teachers challenge students to learn in the context of their place, it is important to integrate local sources of knowledge. Beyond the physical places that prove integral to a place-based approach, human resources are equally vital to the work. In a place-based environment, the disciplinary expertise of teachers and local field experts blends to support students in exploring local issues.

Disciplinary literacy, or discipline-specific thinking tied to reading, writing, and reasoning, is a defining quality of disciplinary expertise. Yet, as Shanahan and Shanahan (2008) describe, disciplinary literacy skills are “...not particularly easy to learn, since they are not likely to have many parallels in oral language use" (p. 45). Therefore, the organic ways in which students develop general literacy (i.e., through listening and talk over a sustained time period) do not usually transfer to their growth in the specialized knowledge required in specific disciplines. Educators using a place-based approach must balance ways to promote understanding of content alongside ways to develop disciplinary literacy skills in order to promote lasting understanding in students. According to Pearson 
et al., (2010), “...without systematic attention to reading and writing within subjects like science and history, students will leave schools with an impoverished sense of what it means to use the tools of literacy for learning or even to reason within various disciplines" (p. 458).

Alvermann and Moje (2013) argue that teaching literate practices “...is as much about teaching youths to navigate the texts, discourses, identities and knowledge of different subject areas, classrooms, and relationships, as it is about teaching word-level skills, discipline-specific vocabulary, or even disciplinary habits of mind" (pp. 10981099). Before teachers can guide students in immersive, contextualized learning, they must feel confident in their literacy instruction.

Like Alvermann and Moje, Tan and Atencio (2016) consider disciplinary literacy skills broadly, defining this sort of "holistic learning" as "...learning within disciplinary subjects to foster pupils' cognitive development, as well as...values-based outcomes such as a confident person with a sense of right and wrong, a collaborative team-player, and a concerned citizen with a strong sense of civic responsibility" (p. 25). To infuse students with a sense of community requires this kind of group collaboration. Overemphasis on either content-related concepts or literacy activities fails to draw out the full potential of a place-based approach. It is the deepening awareness of literate practices, in which students thoughtfully read and question, that builds critical thinking skills.

\section{Disciplinary Literacy Aids Problem Solving}

Ultimately, the purpose of reading and writing extends beyond internal thought and into contextualized problem solving in which some authentic purpose drives the need to know. Place- minded teachers make strategic planning choices with regard to literacy 
instruction, prioritizing disciplinary literacy as a key component of place-based instruction. Shanahan and Shanahan (2008) place disciplinary literacy at the top of the literacy pyramid, where learners take on "...more sophisticated but less generalizable skills and routines" (p. 45). Their study emphasizes the importance of embedding literacy instruction inside secondary content-area classes such as math, science, and social studies. Because disciplinary experts read and comprehend texts in unique, disciplinespecific ways, they best understand the reading, writing, and thinking required in advanced disciplinary coursework.

Harlen (2015) notes the importance of time and expert support in aiding students as they grow to use technical vocabulary in formal and informal ways. For example, students need practice and modeling when listening to others' ideas and results (an informal way of building technical vocabulary skills). They also benefit from understanding the choices when selecting an appropriate format (e.g., drawings, text, tables and graphs) by which to convey technical information. By explicitly noting and routinely modeling and discussing choices made regarding ways to effectively convey technical information, educators can develop in students enduring disciplinary literacy expertise.

By embedding disciplinary literacy instruction into content courses, rather than limiting explicit literacy instruction to English class, learners can better develop in their ability to understand, generate, and respond to texts in specialized, discipline-specific ways. Place-based pedagogy takes disciplinary literacy one step beyond grounding it in a content area class. In place-based environments, literacy growth happens outside the classroom altogether, as content area teachers and field experts ground disciplinary 
literacy growth in local context (Dobbs et al., 2017).

Place-based teaching models promote the development of literacy skills alongside critical thinking skills, allowing relevance and context to drive learning. To effectively participate in the holistic, place-based environment, students require guidance in developing as analytical thinkers who can discern and evaluate the technical, specialized knowledge inside disciplines (Shanahan \& Shanahan, 2008; Fang, 2012). Without this intentional, direct instruction, general literacy skills “...do not automatically develop into more complex skills that enable students to deal with the specialized and sophisticated reading of literature, science, history, and mathematics" (Shanahan \& Shanahan, 2008, p. 43). Working in interdisciplinary teams, place-based educators have potential to facilitate growth in critical thinking. The context provided by place-based instructional models pairs effectively when challenging, discipline-laden texts are used to increase student engagement (Demarest, 2011). For example, by drawing upon multiple sources of knowledge, including historic documents, regional literature, local newspapers, technical writings, and physical artifacts and features, teachers are able to facilitate learning environments that abound with meaning. Students are guided to "look out" (i.e., outside the classroom) rather than "look up" information, as the definition of text expands to include elements not previously considered academic. It is this ongoing cycle of discovery and questioning that creates in teachers and students the desire to make meaning.

The contextualized nature of place-based learning encourages an understanding of connections among academic disciplines (Dobbs, Ippolito \& Charner-Laird, 2017). As they develop greater understanding of disciplinary literacy, teachers exploring place- 
based pedagogy can encourage critical thinking that transcends content area and invites learners to grapple with authentic, broad issues affecting their community. In applying Gee's notion of language play, students can practice slipping in and out of various disciplinary discourses, building their capacity as critical thinkers.

\section{Enacting Place-Based Pedagogy through Professional Collaboration}

While place-minded teachers can range in their implementation practices, uniting them is the belief that meaningful instruction is collaborative, inquiry driven and disciplinary literacy centered. No matter the level of implementation, their investment in building place-based instructional plans requires the commitment to work in professional collaboration with other educators and community members. Specific to place-based pedagogical practices, and in line with the critically conscious thinking of Freire (1983), is the idea that professional learning builds capacity in teacher leaders to consider “...problems related to diversity and equity within schools and society more broadly by considering the roles historical and social activity had in creating these problems" (Wenner \& Campbell, 2017, p. 158). Students in place-based environments learn concepts as they would in typical classroom settings. What sets place-based learning apart is that these academic concepts are contextualized as part of a bigger whole.

When teachers participate in holistic forms of professional learning like this design study demonstrates, the payoff can be an enduring philosophical shift. With overarching professional development goals related to the interchange of content knowledge, pedagogical knowledge, and leadership skills, place-based instructional approach transcends more narrowly focused, single topic workshops or seminars. By committing to such an undertaking, teachers can equip themselves to facilitate rich 
learning with colleagues and students. Place-based professional development, if guided well, offers “...ongoing teacher professional learning that focuses on knowledge and understanding of...histories, cultures and people through proactive engagement with parents and local community members" (Keengwe, 2017, p. 20). Though perhaps more complex than ordinary professional development approaches, place-based professional development offers durable takeaways.

\section{Qualities of Effective Ongoing Professional Development}

These lasting impacts that mark effective professional development programs include professional learning sustained over time, involvement of the same group of educators, and a focus on issues of instruction organized around materials teachers use in the classroom (Cobb, Jackson, \& Dunlap, 2015; Darling-Hammond, Wei et al., 2009; Dunkerly-Bean \& Bean, 2016; Garet et al., 2001; Keengwe, 2017; Wenner \& Campbell, 2017). Dobbs et al. (2017) note that “...professional learning that includes teachers working together over extended periods of time around shared problems of practice lead to meaningful changes in practice more than single-session, one-stop professional development workshops" (p. 34). A team approach to place-based teaching offers the opportunity for this type of professional growth.

\section{Influential Studies Concerning Effective Place-Based Professional Development}

While most studies concerning place-based pedagogy center on student learning, a few have included useful information that relates to teacher professional development. The studies listed below emphasize that the immersive nature of place-based learning leads to enduring professional development similar to the ways in which it leads to lasting student understanding. Because learners (students and educators alike) are 
exploring answers to questions they create, the results are longer lasting. A few studies listed below have special relevance to the current study.

Limmemanstons \& Jordan (2017) emphasize teachers' reports of “...how beneficial it was to have a supportive, collaborative learning group when they developed new curriculum" (p. 5). This small study explored the perceived impact of place-based education (PBE) on a cohort of nine teachers participating in an outdoor wilderness experience. The study reports several aspects of teacher perception, including that PBE leads to stronger engagement, increased collaboration, and deeper understanding of the concepts learned. Professionally, the group reported that PBE led to a greater sense of fulfillment and "an expanded repertoire of teaching approaches" (p. 1). While reported drawbacks included time constraints, lack of support from peers and administrators, lack of funds, and weather, the study ultimately identified more benefits than drawbacks. Like the current study, Limmemanstons and Jordan explore the perceptions of a small cohort of teachers. This study, though, did not focus on interdisciplinary collaboration. While three of the teachers taught subject areas outside of science, the work centered itself around science instruction. Disciplinary literacy was not a focal point of this work. Their findings suggest some difficulty forging and maintaining professional relationships with community partners.

Powers (2004) adds to the body of literature on place-based learning. The mixedmethods study reviewed four place-based learning programs in an attempt to identify common strengths. Ultimately, the areas of strength reported pertained to collaboration. They included effective start-up approaches, buy-in of teachers and administrators, community partnerships, and effective communication. Unlike this study, Powers focused 
on the work with students rather than the professional development for teachers.

Grossman, Hamerness \& McDonald (2009) note the importance of teachers being afforded opportunities to engage in both pedagogies of investigation and enactment (i.e., that teachers can work to investigate issues they deem important and also have time to practice them in increasingly complex settings). Instead of "sit and get" professional development in which teachers function as passive recipients of information and instructional resources, more effective professional learning structures offer the opportunity for teachers to co-participate in activities with "more accomplished" others. By adopting the role of student, teachers can help one another develop pedagogically as they refine new approaches (Bruner, 1996; Deringer, 2017).

Grounding their pedagogy in context through a "...holistic approach to teacher professional learning" provides teachers with necessary space to reflect and collaborate with other educators, focus on experiential learning (for themselves and their students), and reach outside the school walls to build meaningful relationships (Keengwe, 2017, p. 20). Place-based pedagogy, when regularly integrated into instructional planning, impacts students' views of their own learning in ways that transfer to future setting. In comparison with typical professional development models, this work invites teachers to personalize the instructional planning rather than use materials already developed. The generative nature of this professional development experience marks it as unique, since teachers build rather than merely experience the content.

\section{The Gap in the Literature}

While studies on place-based education confirm the benefits of this approach (including increased engagement and collaboration), gaps in the literature leave room for 
further exploration. Whereas most work to date reviews place-based learning from the standpoint of the activities and locations used in program planning, this study explores professional growth in a collaborative team of educators representing a cross section of content areas and grade levels. In this work, we consider the role of place-based learning within an interdisciplinary planning team focused on the disciplinary expertise offered by the collaboration of educators and community members.

While scholars have explored the value of place-based learning, the research surrounding effective place-based professional development is less complete (Austin, 2015; Brooke, 2003; Demarest, 2015; Jacobs, 2011; Elliott, et al., 2016; Lesh, 2011; Oncescu \& Giles, 2014; and Sobel, 2013). Much of the literature has focused on the school and community partnerships that make place-based learning meaningful. More research-based strategies and practices would help teachers attempting to design instruction (both short-term activities and larger curriculum arcs). While the overarching goals of place-based learning have been well documented, practitioners can benefit from understanding how to best approach place-based pedagogy (Austin, 2015; Brooke, 2003; Demarest, 2015; and Sobel, 2013).

Place-based learning literature points to a lack of understanding among experts who do not realize how crucial it is for instruction in all subject areas to include intentional focus on literacy; students benefit when the intentional modeling and use of literacy instruction becomes a predominant focus in middle and high school classrooms (Shanahan \& Shanahan, 2008; Behrman, 2006; Fang, 2012). Adding this literacy focus to a place-centered approach deepens instructional impact. By challenging students to weigh in on difficult issues alongside field experts, place-minded teachers skilled in disciplinary 
literacy techniques compel students to communicate complex critical thinking in organic ways.

\section{Broadening Current Place-Based Models Through Professional Development}

Practitioner-centered theory for place-based learning frequently isolates social studies as a content area, rather than taking an interdisciplinary approach (Lesh, 2011; Marcus, Stoddard \& Woodward, 2012; Percoco, 2017; Selwyn, 2010). While many tenets of place-based inquiry can be extrapolated from an historic perspective into the effective teaching of writing and science, for example, most current research of place-based instruction is grounded in the teaching of social studies (Lesh, 2011; Marcus et al., 2012; Percoco, 2017; Selwyn, 2010).

This current design study attempts to satisfy these gaps by focusing on pedagogical practices that integrate place and learning from an interdisciplinary perspective. Working in teams, teachers use specific places to facilitate student inquiry that transcends discrete content areas through an interdisciplinary approach. Not only will educators expand their own understanding of place-based pedagogy, but they will do so while collaborating with colleagues to consciously consider the interdisciplinary nature of place-based teaching.

\section{Closing Discussion}

To really know a place requires "...an investment of time to understand the local history, culture and ecology" (Tan \& Atencio, 2016, p. 32). More than the physical landscape or constructed venue, place ties to past and present people, economies, events, opportunities and problems. As educators develop their understanding of place-based pedagogy, they recognize these factors and believe "...the place-based approach could 
potentially propel students' deeper engagement with more purposeful learning" (Tan \& Atenciop, 2016, p.32).

Even with the difficulties it poses, place-based instruction provides an enriched educational experience worthy of exploration. The direct relevance to students' lives means that place-based teaching models promote increased engagement and attention. The result is deeper learning that sustains over time (Austin, 2015; Brooke, 2003; Deringer, 2017; Demarest, 2015).

Place-based pedagogy thrives at the intersection of collaboration and inquiry, where content is grounded in immediate context. Drawing its strength from interdisciplinary, literacy-rich routines and professional collaboration, learning originates in the desire to know, building through student-led inquiry into meaningful understanding. Pushing back against the top-down models that too commonly characterize educational environments, place-based pedagogy values learning opportunity grounded in place, since studying "authentic local places and problems enhances students' motivation and critical-thinking skills--and also their grasp of, interest in, and respect for interdisciplinary" (Semken et al., 2017, p. 555).

A place-based model of instruction can strengthen students' reading, writing and reasoning skills as they consider situations and texts. Beyond bolstering their disciplinary literacy skills in a given content area, place-based learning is marked by collaboration. Rather than strengthening disciplinary literacy skills in isolation, place-based learning models challenge students to view learning topics in broad, integrated ways (Allen \& Alexander, 2013). No longer is a classroom topic limited to science or civics. Rather, place-based inquiry invites the use of disciplinary expertise to consider issues in organic 
ways (Selwyn, 2010). 


\section{Chapter 3: Methods}

This chapter details the methods used in this study. It provides an overview of the methodological details of a design study approach based on the work of Reinking and Bradley (2008). After discussing why design study fits the present study and its sociocultural theoretical underpinnings, I outline the procedures used, and describe the context and participants before discussing the data sources, stages of collection, and analytic methods.

It is important to note that other terms are frequently used to describe approaches similar to the design study approach. These include formative research, teaching studies, design-based research, and lesson studies (Reinking \& Bradley, 2008). I chose to define this work as design study because it emphasizes adaptability. Rather than rigidly adhering to research methodology, design study recognizes the complex variables at play in educational settings. Because design studies work in authentic learning environments, they "...seek generalizations from multiple examples rather than from random samples and controlled experimentation" (Reinking \& Bradley, 2008). Design studies use and develop theory in context; they encourage innovation, and, as a result, are more practical in addressing educational goals.

\section{Methodology}

Rather than falling on one end of the spectrum (theory) or the other (practice), design studies aim for a balance of effective practice grounded in theory (Cobb, et al., 2015; Darling-Hammond, et al., 2009; Lampert et al., 2010). Design studies seek to inform practitioners through a relatively broad generalization of findings not specific to a sample population (Reinking \& Bradley, 2008, p. 23). In this current study, it is hoped 
that understandings gained by this team could be applied elsewhere, with other teams in other places looking to improve place-based instruction.

Design studies are not meant to be strictly replicated, but instead to help teachers adapt their practice. Rather than preset objectives, as one might find in a design experiment, the design study approach allows "methodological flexibility" based on the unique learning needs of the situation (Reinking \& Bradley, 2008). The design study approach is useful for the cumulative learning, the gradually developing expertise, of this professional development model.

Jennings et al. (2005) emphasize that practitioners, like all learners, “...filter new ideas through their previous experiences, knowledge, beliefs, dispositions, and the contexts in which they work" (p. 47). Design studies offer a structure for teachers to layer new understanding onto existing knowledge while reflecting and sharing so that success can be adapted, though perhaps not strictly replicated, beyond a single classroom.

Because the design study approach strikes a balance between theory and practice, it seems well suited for this work. Grounded in theory, design studies adapt to changing realities in learning environments, rather than prioritizing the purity of research methods over practical use. Reinking and Bradley (2008) explain that design studies “...intimately merge research and practice, producing findings more transparent and useful to practitioners" (p. 9). In typical educational research models, theory comes first, and “...practitioners have been left to their own devices to determine how research might be applied to their practice" (Reinking \& Bradley, 2008, p. 8). Design studies, though, merge these often separated spheres, considering both "why" of research and "how" of practice. 
By studying authentic educational environments (less controlled than more stringent research environments), these studies seek to understand the complexities of diverse contexts (Cobb et al., 2015). Cochran-Smith and Lytle (2009) emphasize the importance of routinely using local context to design activities. By looking into environmental factors to identify trends, teachers can emphasize issues of equity, engagement and agency to develop new conceptual frameworks to guide instruction. Eventually, thoughtful use of practitioner research can shape school policy and schoolwide structures. Habits and routines that start small can grow to become more dominant building blocks of school culture. By situating questions in the local context and consciously using local stakeholders, teachers can begin to build a climate that merges practice with more explicit attention to the underlying social and environmental factors affecting students.

The authentic environments in which design studies occur, intervention centered and adaptive, are marked by a unique flexibility. While the specific instructional intervention is named and described as central to the work, these experiments are open to “...important unintended consequences," and researchers remain sensitive to positive or negative unanticipated effects produced by a classroom intervention (Reinking \& Bradley, 2008, p. 21). Cobb et al. (2015) explain that “...existing instruments are often not adequate because classroom design studies typically aim at novel learning goals" ( $\mathrm{p}$. 18). The uncertainties of the design study approach make it necessary for researchers to be both flexible and original in their design and application.

Furthermore, design studies align with sociocultural theory. The idea that social interaction and environmental factors affect learning is grounded in the theory first 
identified by Vygotsky (1986). Learning environments rich with interactive encounters with people and places lead to deeper understanding. The social nature of learning lends itself to the collaborative, inquiry-driven qualities of place-based instruction. Those adopting a sociocultural perspective see language as social, believing that understanding forms through interacting with others on all levels, including through the use of language. Believing that actions cannot be separated from the environment in which they occur, sociocultural theory sees language development and learning in general as something that results from human interaction. In the context of this study, sociocultural perspective is relevant because there is value placed on local context. Local surroundings (both the places and the people) are integral to learning.

\section{Details of This Study}

This design study used a design-based, formative approach to consider teachers' understanding and use of place-based pedagogical practices. Based on Reinking and Bradley's (2008) approach, the study focused on teachers' awareness, understanding and use of place as they implemented classroom instruction and built a professional development experience for colleagues. Believing that educational research should be of immediate use to practicing teachers, and not strictly theoretical, design studies consider pedagogy from both theoretical and practical perspectives. Rather than a tightly controlled research setting, the flexibility of design studies allows in-progress adaptation.

Participants in this design study included a team of classroom teachers interested in exploring place-based instruction. Coming from a range of classroom backgrounds (in terms of experience, grade levels, and content areas), this team of teachers considered place-based pedagogy both in their classrooms and as they collaboratively designed a 
professional development experience for other educators. While the design study spanned three months as teachers planned, implemented, and reflected on place-based pedagogical shifts, the participant group formed three years earlier. Prior to the start of the study, teachers had participated as part of a leadership team guiding the development of the local place-based professional development model. Following the initial National Writing Project design workshop described in Chapter 1, regular meetings began. Quarterly, the leadership team met, sometimes on the school campus during district professional development days and sometimes in the museum classroom. During these sessions, the group reviewed professional literature about place-based learning and teaching, wrote and read about place, developed model lessons and visited local places in search of sites that would become key to the work. Teacher insights provided in interviews and written reflections refer back to a time prior to the start of the study. Like other design studies, this one takes a practical, adaptive approach to learning. In this case, thinking is related to place-based instruction.

At the heart of the research is the question of how a place-based instructional perspective impacts teaching. By documenting the factors that promote movement toward a specific pedagogical goal (the effects of a place-based instructional approach), the study captured how increased understanding of place impacts teaching. Existing literature on PB pedagogy marks certain qualities as present in place-based models, marking this instruction as inquiry-centered and collaborative in utilizing disciplinary expertise. These qualities align with state education standards. In studying place-based pedagogy through a design study approach, adjustments could occur throughout rather than privileging the purity of the research process over its practical application. 


\section{Problem Statement}

The focus of this study was to explore the benefits and drawbacks of a placebased pedagogical framework. It centered on a group of local teachers as they collaboratively create a sustainable professional learning experience at the Walt Disney Hometown Museum while also implementing place-based pedagogy as part of their individual classroom practices. The study used a design study approach and called upon ethnographic methods to analyze interviews and written participant reflections.

Instructional materials were reviewed as well, as the group collaborates to form a placebased professional development experience for teachers outside the local district. This study examined the professional impact of teachers' sense of place as they worked with students and colleagues to implement a place-based instructional approach, both in their classrooms and as they designed professional development for colleagues. 


\section{Table 1}

Timeline of the Study

\section{Main Question:}

How does a sense of place impact teachers?

Sub Questions:

How does place impact their professional identities, classroom decisions, and professional relationships?

\section{Data}

Individual Interview I

September $2019 \quad 60$ minutes

Individual Interview II

October $2019 \quad 30$ minutes

Individual Interview III

October $2019 \quad 30$ minutes

Group Panel

November 201945 minutes

\section{Analysis Methods}

Interview responses were transcribed and analyzed for patterns regarding participants' thinking about professional identity, pedagogy and professional/community relationships.

The interviews followed a protocol that emphasized the following:

Interview I: Focused Moments of Life History

Interview II: Details of Experience/Practice Interview III: Professional Growth/Future Planning

This group discussion was videotaped (with audio), transcribed, and analyzed for patterns regarding participants' discussion about similarities and differences among participants.

Weekly Reflective Notebook Entries

October -

November 2019 Weekly

Individual interview responses were analyzed for patterns regarding participants' thinking about professional identity, pedagogy and professional/community relationships. In particular, reflective notebook data were analyzed to uncover thinking about place, disciplinary and critical literacy, 


\begin{tabular}{|c|c|c|}
\hline & & $\begin{array}{l}\text { inquiry, and interdisciplinary } \\
\text { collaboration. } \\
\text { Using a digital platform allowed the } \\
\text { entries to be dialogic in nature, with } \\
\text { exchanges occurring between the } \\
\text { researcher and each participant. }\end{array}$ \\
\hline Data & & Analysis Methods \\
\hline $\begin{array}{l}\text { Instructional Materials } \\
\qquad \begin{array}{c}\text { Pre } \\
\text { Post }\end{array}\end{array}$ & $\begin{array}{l}\text { September } 2019 \\
\text { December } 2019\end{array}$ & $\begin{array}{l}\text { An early and revised sample of each } \\
\text { teacher's place-based lesson } \\
\text { materials was reviewed in order to } \\
\text { compare their thinking about } \\
\text { professional identity, pedagogy and } \\
\text { professional/ community } \\
\text { relationships. An analysis of } \\
\text { instructional materials showcased } \\
\text { how, in place-based instructional } \\
\text { design, pedagogical decisions impact } \\
\text { logistical details such as workshop } \\
\text { scheduling and instructional } \\
\text { sequencing (as discussed in Chapter } \\
\text { 4). }\end{array}$ \\
\hline \multirow{2}{*}{\multicolumn{2}{|c|}{ Field Notes / Conceptual Memos }} & $\begin{array}{l}\text { The researcher gathered notes during } \\
\text { individual interviews and during } \\
\text { instances of professional } \\
\text { collaboration to compare the } \\
\text { participants' thinking about } \\
\text { professional identity, pedagogy and } \\
\text { professional/ community } \\
\text { relationships. In particular, this data } \\
\text { was analyzed to uncover thinking } \\
\text { about place, disciplinary literacy, } \\
\text { inquiry, and interdisciplinary } \\
\text { collaboration. }\end{array}$ \\
\hline & & $\begin{array}{l}\text { Each week, conceptual memos were } \\
\text { created involving multiple samples } \\
\text { of data. }\end{array}$ \\
\hline
\end{tabular}

\section{Participants}

Six teachers joined the study. This group varied in years of experience and area of 
content expertise. They shared an interest in and willingness to explore place-based learning. In particular, this study explored how a heterogeneously trained group of teachers (i.e., those teaching differently aged students in ranging academic disciplines) collaborate professionally to promote learning through a common sense of place.

Abby: A recent college graduate, Abby has accepted a position with the local school district to instruct all agriculture courses while also overseeing the Future Farmers of America (FFA) Club. Instead of a basic classroom, Abby’s instructional area includes 5,000 square feet of space. With state-of-the- art audiovisual equipment, a shop for building and welding, and a greenhouse, she oversees students enrolled in a range of agrelated courses while also facilitating members in their quest to compete at regional and state levels in a number of FFA contests. Abby brings a fresh perspective to the leadership group, as she is both new to the area and new to the field of education.

Tori: Tori is a twenty-two-year veteran teacher who instructs a mix of entry and upper-level science courses. While she has taught in the district for just over twenty years, she moved to town more recently: nine years ago. This decision was made to better accommodate her own children, who were becoming active in school activities. Having taught locally for a number of years prior to relocating as resident allowed an easy transition into the community. Professionally, Tori has always exhibited an eagerness to learn. She regularly elects to participate in professional development opportunities and has become known in the region as an expert often called upon when leadership roles are available. Tori is especially versed in disciplinary literacy and actively seeks new ways to incorporate literacy routines and practices when planning instruction.

Andrea: Like Tori, Andrea has taught in the district for about twenty years. Her 
teaching load consists of high school social studies courses serving students in grades nine through twelve. Each year teaching in the local district, Andrea has commuted from her own hometown approximately sixty miles away. She does not identify as part of the local community, but instead lives in the town in which she grew up and sends her own children to the school she attended. Like Tori, Andrea seeks out professional development opportunities and has over time built extensive knowledge about ways that content teachers can infuse literacy into their classroom on a routine basis.

Dave: Dave is currently entering his eighth year of teaching, and is in year six teaching in the local district as a middle and high school social studies instructor. One of four siblings, he is the only one to return to town following college. Dave's family extends back for generations in the area. He spends a great deal of time coaching extracurricular activities. His knowledge of and interest in local history contributes meaningfully to discussions, both in the classroom with students and during professional development planning sessions.

Chelsey: Chelsey has taught at the local elementary school for eighteen years. Born and raised in the district's town, she decided to return following college, where she took a job teaching. For a number of years, she taught other grades, finally landing a position in kindergarten when her teaching partner, Lillian, transferred to the same elementary school.

Lillian: A fifteen-year veteran to school teaching, Lillian has been Chelsey's hallway neighbor and teaching partner for seven years. She too grew up locally, returning after college but working at a neighboring district for the first nine years of her career. Unlike Chelsey, who left pharmacy school to pursue an education degree, Lillian has 
always known she belonged in an early elementary classroom.

Lillian and Chelsey now team teach the kindergarten group, always working collectively to make decisions and plan instruction. The centers-based approach they use in creating learning stations pairs well with the theory of place-based learning. They also contribute to the group by possessing a deep knowledge of the community. Both served as youth ambassadors in their high school years, and come with deep knowledge about the town's history having been required to know it to serve in that role. As adults, they continue to use their knowledge of local history to impact professional decisions.

\section{Research Setting - The "Place" of the Work}

The research took place in and around the local museum, based on a famous historic figure, inside the fully restored 1913 Santa Fe Depot. The Museum campus consists of two buildings, one large and one small. Adjacent to the railroad tracks, seventy trains still pass by each day as a reminder of the town's railroad history. A recently renovated Museum classroom on the second floor allows a prime view of the city park and the downtown district, two additional key locations in the work. The Museum is located one block from the school campus, allowing easy movement between the two locations. Two farms were also key in the work, both an easy drive from the Museum. These off-campus sites provided a break for the workshop planning team. The nature of the place-based pedagogical work leads to the physical locations being as integral as the people in designing and testing out the workshop activities. In the early meetings, prior to the start of the study, the teachers first gained a sense of the locations integral to the work. These early visits were key as teachers decided not only the content of model lessons, but also the locations. 


\section{Researcher Positioning}

Having already spent time with most in the group (in the context of the workplace), I saw myself as a collaborator (Heath \& Street, 2008) in this work. Because I was aware of the possibility for tension in the group due to the uncertainty of the direction the work would take, I left communication lines open. With the exception of the first-year participant, the others and I have worked alongside one another for years. I believe our open communication flow supported and enhanced a thriving research context. Our group has a history of working together in varied combinations on other professional initiatives. We have existing patterns of open communication, and also benefit from strong administrative support for this work at the building and district levels. I emphasized from the outset that the design study would welcome, rather than resist, feedback leading to adaptations throughout the study.

\section{Data Collection}

Data collection included the following types: interviews, reflective notebooks created by teachers, field observation, instructional materials, and conceptual memos. I collected multiple samples of each data type.

\section{Interviews}

I conducted a series of three interviews spread across three months with each of the participants. An initial interview lasted sixty minutes and followed a semi-structured design to help frame the participants' professional experience and sense of community (Quinn, 2005; Weidman, 2013; Merriam, 2009). Two follow-up interviews of approximately 30 to 45 minutes touched on follow-up questions and new insights while adhering to a focus as described below. The interviews included pre-written topics but 
allowed time for interviewees to freely express ideas, even if somewhat tangential (Quinn, 2005). The interviews took place at the convenience of the interviewee (in terms of both time and place). Following a series of three individual interviews, a group discussion of approximately forty-five minutes occurred to capture participants' collective perspective on the value and use of place as professional educators.

Using a semi-structured design, I guided all interviews with open-ended questions (both main and follow-up). Except for the final group panel discussion, each interview was conducted individually, after which I made notes in my reflective notebook.

By design, the first interview represented a brief life history (as participants considered their identity both as self and as teacher). Questions related to stand-out moments (both good and bad) that propelled each teacher forward personally and professionally. This interview served as a detailed introduction to each participant, but also worked to make the group more conscious of their place orientation.

Interview two took place during October 2019 and lasted thirty to forty-five minutes. I used an open-ended structure to follow up on topics raised during the initial interview as well as reflective notebook entries in order to grasp participant perspective on place-based pedagogy and on teaching in general. The second interview focused on capturing details of the group's teaching experience, including information on typical work days, work relationships, professional frustrations and rewards, and organizational/logistical details related to lesson design and implementation.

A third individual interview occurred during late November 2019 and followed a similar duration, lasting about forty-five minutes. This final one-on-one interview asked participants to reflect on the previous conversations and think about them in the context 
of the educational environment in order to uncover situational factors that impacted their teaching. Also during this session, each participant was asked to think about the ways in which the lessons evolved over time

A group panel discussion completed the data collection. Following a series of individual exchanges between the participants and me (through interviews and notebook entries), I brought the group together for a discussion that allowed them to build upon and possibly contradict one another. In order for the collaborative nature of the work to show through, I thought it was necessary to engage in this sort of group discussion (Wodak \& Meyer, 2016). I videotaped and audio recorded this meeting in order to grasp the subtleties of the interaction among project participants. This allowed me to record and analyze both verbal and non-verbal observations.

\section{Field Notes}

During the months of data collection, I used the structure shared by Heath and Street (2008) to make notes. The final discussion was both audio recorded and videotaped, offering an additional opportunity to see and hear teacher interactions. Included in the notes were the following components: a running account of events, the capturing of "notable short phrases," and noticings related to changes in the setting, personal interactions, etc. I reviewed the videotape multiple times, with and without sound, to note the subtleties of teacher interactions through verbal and non-verbal communication. Leavy (2017) describes the importance of capturing "on-the-fly" words and phrases, the short direct quotes that happen, often during informal moments. These, coupled with the more detailed thick descriptions, provide a complete picture of the work. Leavy (2017) explains that carefully crafted field notes can later help the 
researcher develop ideas through the processes of integrating, synthesizing, and discerning.

\section{Instructional Materials}

As leaders in designing a professional development experience at the Museum, the participants developed instructional materials that utilize principles of place-based learning: collaboration, inquiry-based and disciplinary/literacy-centered. I collected an early draft of planning materials at the conclusion of a professional development meeting. At the final interview in December, I collected a revised version in order to compare these documents using a protocol developed for the study (Appendix B). A review of instructional materials provided information about the participants' developing understanding of place-based instruction. Along with observation and interview notes, I gained a sense of teachers' developing understanding by reviewing instructional materials. I include highlights of a discussion about their evolving thinking with regard to changes in lesson materials in Chapter 4. The "unobtrusive methods" used to analyze content and materials provide a useful contrast to the interview data and participant reflections (Leavy, 2017, p.145). Because the data are "nonliving," they exist apart from the research and are, therefore, more naturalistic (i.e., imbued with fixed, embedded meaning).

\section{Participant Notebooks}

From the first through the final interview, each participant contributed weekly notebook entries. These reflective entries include thoughts about place-based professional development, including ideas about curricular planning, concerns, interactions with colleagues, and, of course, frustrations. By housing these digitally, I made the notebooks 
interactive by responding to each entry in between sessions. This group was already comfortable with Google Docs prior to the start of the study, and with folders and permissions, making it easy to create and maintain a system that eliminated any difficulty in sharing work. We structured the shared notebooks using digital platforms already familiar to the teachers due to the use of Google in their daily work as teachers and employees of this Google-friendly district.

The frequency of these entries was fueled by a desire of participants to respond, though I did ask for feedback at least weekly. The digital notebooks allowed for easier exchange between each participant and me (i.e., we did not have to schedule a conversation each time they wished to respond). I, too, kept a researcher's notebook detailing my own experience alongside responses to my interactions with participants (in person and through notebook exchanges). These reflective data sources complemented interview data, allowing a more complete picture of "presuppositions" and perspectives (Hill, 2005).

\section{Conceptual Memos}

Each week during the research period, I wrote conceptual memos in conjunction with field notes. Included were ideas, questions, and reflections as prompted by the data. More than a list or record, conceptual memos allowed analysis to be part of (though separate from) the data collection process (Quinn, 2005; Seidman, 2013). Here, I had an ongoing place to make note of concerns and setbacks, but also patterns, insights, and breakthroughs. This allowed some reflection to occur as the interviews were happening; this approach aligns with Leavy's (2017) description of data analysis as a recursive process, continually moving between analysis (including summarizing and organizing) 
and interpretation (finding and making meaning).

\section{Data Analysis}

My data collection produced five main types of data for analysis: interview data, reflective notebooks created by teachers, field observations, instructional materials, and conceptual memos. As described by Leavy (2017), the analysis included five phases following data collection. The data preparation phase included organizing digitized transcripts into a repository divided by participant as well as cycle (i.e., interview one, two or three). This method of organization allowed me to look at individual participants across time to note potential changes in perspective and also to look at the group's collective shifts. Though I used an automated transcription tool, I manually "cleaned up" the file sets by labeling speakers and removing some superfluous utterances (Heath \& Street, 2008).

Following each interview, I completed an initial immersion into the transcript (Leavy, 2017). In order to best "feel the pulse of the data," I read the piece of data carefully through twice. I reviewed each piece within its category carefully in an effort to tease out patterns. As defined by Heath \& Street (2008), the analysis used ethnographic tools to study aspects of practices of the group: an interdisciplinary team of educators exploring ways to understand and implement place-based learning (both individually and as a team). Of particular use were the ethnographic tools such as interview transcripts, document content analysis, and digital sound recording.

Following the initial read-through to get a general sense of the data, I next more actively reviewed the text. During the third review of the data, I made marginal notes, annotated and circled important, confusing or contradictory ideas. To best capture shifts 
in pedagogical approach, both subtle (micro-level) and major (macro-level), I completed this phase with the research questions displayed as I worked. The notes I made constantly considered how the transcripts, reflections and materials reflected teachers' connection to place. I looked for signs of teachers consciously considering place in making instructional decisions and in connecting with colleagues.

Heath \& Street (2008) describe how ethnographic methods allow researchers to study the ways in which humans gain expertise through learning situations as individuals, in groups, and while connected to societal institutions such as schools. The use of ethnographic methods revealed how participants identify as individuals and in shifting groups, all the while making sense of the world and using language to describe it. An understanding of ethnography provided a heightened way to make meaning from recorded language and observation. Using ethnographic methods to capture teacher perception allowed "...ways to enter into the life of the individual, group, or institutional life of the 'other'" (Heath \& Street, 2008, p. 31). Each instance of data immersion shed light on how the teachers' encounters with place shaped their individual and group identity.

Using ethnographic methods required a careful look into systematic approaches to gather and analyze data. Through a cultural analysis of discourse, we gain a "window into cultural understandings and the way that these are negotiated by individuals" (Quinn, 2005 , p. 3). Deep exploration into the art of interview allows research that interrogates the questions in meaningful ways, delving deeper than word meanings and into the related cultural understandings. Interview structure, as outlined by Seidman (2014) provided participants the chance to "...reconstruct his or her experience within the topic of 
study" (p. 14). Using primarily open-ended questions, the goal involved exploring complex issues by capturing concrete views and experiences of the participants. Encouraging participants to respond in detail (without tight structure) yielded ample interview data, enough to analyze for evidence of patterns and relationships.

Rooted in a phenomenological approach, the three-interview series focused on participant experience and on the act of making meaning from experience (Seidman, 2013). This contextualized approach, the attempt to understand another's experience through his or her point of view rather than through our own, recognizes that subjective nature of meaning making.

Knowing that clarity of experience is transitory, language bound and situation dependent, the phenomenological approach recognizes the significance of context in data interpretation (Seidman, 2013). Extending participant reflection into a three-part series allowed patterns to be formed and reviewed over time, rather than risking misinterpretations more likely in a single interview.

Once the data had been reviewed carefully and annotated, I began to categorize and determine themes in order to develop findings. Because I relied on ethnographic methods to note how the team identified as part of an emerging group (Heath \& Street, 2008), I did not code the data using exact language. In an effort to grasp the transition of the team, I instead looked for patterns across the group — signs of pedagogical similarity or discord. Seidman (2013) describes the “...tentative interpretations that begin to influence the path" of questioning (p. 130). This work involves not only marking key passages and letting them speak for themselves, but asking what the lines mean. Seidman (2013) emphasizes the need to identify and explain the "connective threads" that weave 
participant responses together (p. 130). Here, it is important for the researcher to note misunderstandings, surprises, confirmations and contradictions.

\section{Limitations of Research}

A number of limitations accompany this work. The limited data-collection period and small group size, though in line with the professional development sequence, may not reveal teacher change entirely (as some is likely to continue following the conclusion of the research). Teachers in this study have ties to a very small local community which is defined in some specific ways. A railroading and coal mining history continue to permeate the local identity, as many residents take pride in furthering the narrative and exploring this facet of local history. The group remains constantly mindful of the ways in which use of local sites might not transfer directly to other communities, understanding that other rural towns have equally narrow histories that might not exactly match this one. As such, reflections included an increasing understanding by the group of the need to embed processing time into the workshop schedule in order for participants to have space to think about how activities can transfer to alternate locations.

\section{Limitations of Implementation}

In addition to the aforementioned limitations of this research are a few general limitations tied to implementation. The complexities of learning (for both students and teachers) make it impossible to specify all phenomena occurring in a learning environment. This means that teachers attempting to undertake similar work might struggle to replicate or adapt a similar approach given the many variables at play. Because the team is relatively new to a place-based approach, more work is needed in the area of personalized instruction to meet student need. Context poses another 
possible limitation, as it is impossible to insulate place-based pedagogy from the specific school environment in which it occurs. Environmental factors within the school affect the teachers' ability to carry out the work beyond the classroom. While it is hoped that teams can gather and plan through discussion prior to the start of the work, the reality is that certain factors, even if they are known to be less than ideal, may be outside the control of classroom teachers. While existing relationships between school and community can strengthen or expedite the place-based work, these ties can potentially complicate planning and implementation. The complexities of human relationships add potential to the work, and also a layer of challenge that teams must work through.

\section{Ethics}

Each participating teacher completed a signed consent form. To maintain confidentiality, I used pseudonyms throughout the time I worked with data or provided drafts to participating committee members. I kept all writing and data in a secure location, sorted by interview date and locked (Merriam, 2009).

When identifying patterns and forming conclusions, I utilized multiple sources of data. I shared initial analysis with participants to see how their perceptions line up with mine. Since we utilized the three-part interview series, I had the opportunity to share my preliminary findings with them and to offer the chance to respond to the narratives as requested. It was my goal throughout to allow time for them to respond individually and collectively with shifts in thinking.

\section{Potential Benefits}

Even given the potential difficulty of working with a familiar group, the idea of 
leading professional development related to place has immediate and long-term advantages for the collective good of education. This approach naturally lends itself to current initiatives, including integrated, interdisciplinary learning and professional collaboration. As indicated in the literature review, this approach ultimately leads to an enriched, meaningful learning experience for students. 


\section{Chapter 4: Findings}

Many teachers enter the education profession to positively impact schools and society through effective instructional practices resulting in student learning. While styles and approaches vary, a commonality found among many teachers is to engage students in lessons that are relevant and useful. By drawing upon that which is accessible and familiar to students, teachers can use place to provide the initial "hook" that fuels student learning. Grounding instruction in known places, people and contexts adds relevance to learning situations. This is the central aim of place-based education.

In this design study I explore the benefits and challenges of a place-based pedagogical framework. In this chapter, I analyze the professional growth of a team of teachers from an area school currently engaged in developing a sustained place-based professional development program. By capturing their experiences and evolving thinking, I compare the experience of this team with the larger pool of research surrounding placebased pedagogy. For the purposes of this study, it is important to remember that participants implemented place-based pedagogy as both classroom teachers and as professional development leaders. As outlined in Chapter 3, interview questions were framed using a three-part interview protocol to grasp the perspectives of participants as they considered their professional roles. I used a design study approach to explore the teachers' views on place-based pedagogy. This process involved analysis of interviews, written participant reflections, and place-based instructional materials developed and revised by the teachers.

The following research questions were used to guide the study and capture how participant perspectives surrounding the idea of place took shape: How does sense of 
place impact teachers? How does place impact their professional identities, classroom decisions, and professional relationships?

\section{Overview of Data Analysis Procedures}

Following the first round of interviews, I began analyzing data. This included both interview transcripts from Interview I and responses to weekly participant reflections. My field notes included comments about each form of data collection, color coded to align with the major elements of place-based pedagogy as noted in Chapter 2 (where it is described as collaborative, disciplinary/literacy centered and inquiry driven). Following an initial round of color-coding according to defining themes, I reviewed all participant data a second time to search for patterns among responses; I searched for both repetition and signs of dissention. These notes I included in weekly conceptual memos (Quinn, 2005; Seidman, 2013), the reflective notes I kept during the data collection phase that allowed ongoing thinking about patterns, anomalies and resulting questions evident in the individual interviews. This careful note taking and observation of teachers during individual and panel interviews gave me the opportunity to draw upon the ethnographic methods outlined by Hill (in Quinn, 2005), who emphasized the production and enactment of culture through spoken interaction. Because narrative includes analyzing shared as well as emergent understandings, review requires careful attention, or, what Hill (in Quinn, 2005) describes as "inferential reasoning" on the part of the researcher (p. 160). This understanding develops over time and allows useful comparisons - and contrasts - to be drawn.

\section{Overview of the People and Places in the Study}

Table 2 lists participant details relevant to place identity. It shows the range of life 
and professional experience, as well as the range of disciplinary expertise. The local planning team is, with the exception of one first-year teacher, composed of educators who have worked together prior to this project. Previous place-based studies have, like this study, explored place-based learning and instruction. What sets this work apart is the focus on bringing together a local team of educators to build, rather than merely experience, professional development. For three years, this team has engaged in the planning and development stage to create animmersive professional development experience in partnership with a local museum based on a famous historic figure who grew up in the area.

The planning team is interdisciplinary and cross-grade level. The professionally diverse experience of the group allows us to discuss and model the disciplinary/literacy components fundamental to the program design using a range of professional disciplinary expertise. Just as the group possesses different academic and disciplinary strengths, they also primarily instruct and understand students at different grade levels. 


\section{Table 2}

Table of Participant Information

\begin{tabular}{|c|c|c|c|c|}
\hline \multicolumn{4}{|c|}{ Years in } & \multirow{2}{*}{$\begin{array}{l}\text { Job } \\
\text { Placement }\end{array}$} \\
\hline Participant & Education & District & Locality & \\
\hline Dave & 8 & 6 & Teaching in hometown & $\begin{array}{l}\text { MS/HS } \\
\text { Social } \\
\text { Studies/Coach }\end{array}$ \\
\hline Andrea & 23 & 21 & $\begin{array}{l}\text { Commutes } 115 \text { miles per day to } \\
\text { teach }\end{array}$ & $\begin{array}{l}\text { HS Social } \\
\text { Studies }\end{array}$ \\
\hline Tori & 22 & 22 & $\begin{array}{l}\text { Grew up in similar town } 20 \\
\text { miles away; commuted for } 13 \\
\text { years before relocating as } \\
\text { resident }\end{array}$ & HS Science \\
\hline Abby & 1 & 1 & $\begin{array}{l}\text { Grew up in larger district } 30 \\
\text { miles east of town }\end{array}$ & $\begin{array}{l}\text { Ag Instructor/ } \\
\text { FFA Sponsor }\end{array}$ \\
\hline Lillian & 15 & 7 & $\begin{array}{l}\text { Returned to town after college; } \\
\text { commuted to neighboring } \\
\text { district for first } 8 \text { years }\end{array}$ & Kindergarten \\
\hline Chelsey & 18 & 18 & $\begin{array}{l}\text { Returned to teach in town after } \\
\text { college }\end{array}$ & Kindergarten \\
\hline
\end{tabular}

\section{Description of PD Program at Center of Study}

As discussed in Chapter 1, the Museum Here and Now! Place-Based Workshop has evolved from the early planning stages into what is now a well-developed professional opportunity for rural educators in the region. The initiative draws on the cross-disciplinary collaboration of the leadership team willing to devote time and energy to test and refine the workshop's key activities and readings, continually using question-centered approaches to foster an environment of inquiry. Community members have willingly engaged with the planning team to strengthen the program; key partners include local historians, local representatives from the 
Missouri Department of Conservation, city officials and local law enforcement.

The Museum has served as the main partner on the project, offering physical and human resources to the team of educators engaged in this work, even serving as the sponsoring institution. From the planning stages, including developing the leadership team and advisory committee, to a pilot workshop to test sequencing and impact, the group has undertaken all aspects of the work. They will attempt to secure funding to implement the experience in full form by the summer of 2021. The workshop structure developed and piloted by this team includes interdisciplinary, place-centered lessons presented alongside reflective activities. Ultimately, the goal is twofold: teachers will experience collaborative lesson design along with the opportunity to step back and consider ways they can build similar lessons in their respective places (see Appendix A for full detail of workshop agenda).

\section{Findings}

In exploring the question of how sense of place impacts teachers, four main findings resulted from this study. Careful review of the interview and reflection data, in conjunction with current instructional materials, led to these findings. By analyzing the place-centered experiences of this team of teachers, it is clear that their evolving sense of place is integral to their sense of personal and professional self. Also evident is that sense of place connects to teachers' unique expertise and is a noteworthy factor in guiding classroom decisions. This team has used their evolving sense of place to build professional relationships important to inquiry-driven collaboration. Ultimately, they have grown professionally in broad ways by engaging in this work. 


\section{Sense of Place is Integral to Sense of Self, Becoming Part of Personal and \\ Professional Identity}

As discussed in Chapter 3, this study explored how a diversely experienced group of teachers (i.e., those teaching differently aged students in varied academic disciplines) collaborate professionally to promote learning through a common sense of place. Given its sociocultural underpinnings, place-based pedagogy has the potential to bridge communication gaps and build a common knowledge base. Place is integral to identity, impacting both individual perspective and shared understanding among a learning community. Underlying the collaboration among students and teachers is the influence of place on identity. To understand teachers' application of place-based pedagogy, it is first necessary to grasp their thinking about place in general. Who we are is influenced by place starting at an early age, even before we are consciously aware of its impact (Flower, 2008; Freire, 1983; Lesh, 2011; Moffett, 1988). This first finding, of place as integral to identity, is worthy to stand alone as a main finding. The idea that place impacts personal and professional identity is also fused into the other findings, since it is impossible to separate teachers' identities from the work they carry out.

For the group of participants in this study, early place-centered memories as shared in the interviews continue to impact who they are and how they teach. Their tie to place represents a range of local and regional experiences. Some of the participants (Dave, Lillian, and Chelsey) were born and raised in town, and share early memories of the places integral to the place-based workshop and local school campus. Each of their families has been deeply rooted in the community for several generations. Others, including Tori and Andrea, do not name the local community as their place of origin, but 
still spend significant time living and/or working in this community as adults. One participant (Abby) is a newcomer to both the town and the notion of place-based work. Common among the group is a rural background. Whether raised in the local community or a surrounding one, the participants' interview responses indicated a similar rural frame of reference.

The place-based professional development work in this study has evolved as a school and community partnership centered at our local museum. For two of our participants, Chelsey and Lillian, volunteer work at the museum started long ago when the two were elementary students. For a period of twelve years, beginning around age six, they belonged to a group of local youth ambassadors who worked with museum personnel to guide visiting tour groups. For them, the museum and surrounding grounds hold a special place of significance rooted in memory.

Chelsey commented on that in her reflective notebook:

Chelsey (Reflective Notebook, November, 2019): I now understand that the place isn't an end, but a bridge to the idea of working together and talking about things, asking questions. I have so many memories of E.P. Ripley Park. And even though it could be any park, anywhere as far as the physical qualities go, the fact that it's Ripley helps me work with the students because I have so many memories. When I was their age, I played in that park. I helped Kaye [founding member of Museum Board] give tours; I probably fought my little brother. So for me there is a connection that helps ground the learning. And I hope the kids will feel that same connection grow as they learn and play in that place.

Like Chelsey, Lillian has childhood memories that relate to the spaces used for workshop 
activities. Lillian returns to the importance of narrative when thinking about how youngsters develop a sense of place:

Lillian (Interview I, September, 2019): In my mind, I see the photographs of Walt Disney standing in the doorway of the Zurcher Building--it looks the same then as now. And I think how special it is for our young people to have the chance to walk the same streets and know the same places as Walt Disney. To see those brought to life in Disneyland and on the movie screen as his memory recreates moments from his childhood. Our kids have this in a more visible way thanks to his creative powers. But all kids use story to gain understanding, and just think of how those stories always center around certain places. You see kitchens and farm fences, or you see city streets and bus stations maybe, but if you are human, place matters.

In this single statement, Lillian captures the significance of the study and of placebased pedagogy. Both she and Chelsey developed a rich sense of place at an early age in both private and public capacities. In addition to the family-centered locations they value from childhood, Lillian and Chelsey also developed a place-centered public role earlier than most as a part of the museum's youth ambassador program. Working with colleagues and students in this space is an activity rooted in experience and memory which influences their professional identity. For them, there are local places that continue to hold meaning in overlapping ways sustained over time. Personal memories utilize background knowledge and influence the teachers professionally as they create a placebased learning environment.

In another example of personal experience influencing professional identity, 
Dave's local family roots and interest in the area have proven beneficial. He is able to recall details that aid in planning and implementing instruction, such as his understanding of people and places in the community. When questions surface pertaining to program planning, his knowledge often provides clarity and perspective. Dave remembers facts and has knowledge of current and historic land ownership that proves useful in thinking through program activities centered on area Century Farms. He knows the names visible on plat maps, often helping trace ownership using maiden names. In addition to the usefulness of his knowledge during planning sessions, Dave's use of family history also helps when discussing the area in class with students. He explains how knowledge of the area and people promotes class discussions:

Dave (Interview I, 2019): I'm from this area and I know a lot of them. I know a lot of their families and I know their history and stuff like that. Knowing these things gives me something to talk about and gives me ideas of things that will start to get them thinking and talking.

This trend of incorporating local families into class discussions shows one informal use of place-based learning. Dave's awareness of place and people (including family connections) supports both his personal and professional identities. He ties local knowledge to classroom instruction helping students make similar connections.

Another example of program planning relates to a "breakout" activity intended to familiarize workshop participants with local history in and around the museum. In this activity, the team builds clues to lead future participants in a game that will serve as a teambuilder and as a way to build context for participants familiarizing themselves with the museum and surrounding community. While developing the activity, a number of 
questions came up, and Dave's local knowledge aided the group. As shown below, when asked about how he used knowledge of local people and places to build the clues, Dave noted how a similar approach allows him to add value to the discussion of historical events in class:

Dave (Reflective Notebook, October 2019): If you think of the historical time period, like post-Civil War, you can think about which families were established here early and almost always find someone whose life was affected by it. My great-grandfather left a picture of himself with two neighbors. That picture is valuable from the sake of early photography. But here, it is so much more valuable because neighbors then continue as neighbors now. We are talking about one hundred and fifty years of land ownership traceable. Think of the historic significance of that. How many places could trace land ownership like that, through existing families? It is unique to our rural way of life.

This is one example of how workshop planning has been enriched by local expertise, including the organic, internalized way of knowing local places, culture, and people. Members of the leadership team who grew up within the community offer insight through deep-rooted understandings that reading and studying simply cannot replicate.

This contextualized awareness of public space aligns with a phrase used by Ellsworth (2005): "pedagogically charged spaces and events" (p. 22). Her work emphasizes the visceral effect that important places have on physical and cognitive aspects of student growth. She notes that learning is knowable only when learners respond to pedagogical components, since they can "...be enabled and enhanced by the kinesthetic, leading to hands-on, holistic and project-or arts-based approaches to 
teaching” (p. 23). The collective research supports the same connection between physical place and developing understanding that this group of teachers demonstrated (Brooke, 2003; Demarest, 2015; Donehower et al., 2007; Ellsworth, 2005; Percoco, 2017; Sobel, 2013). Recurring findings in the research about the benefits of place-based pedagogy proved true with this local team as well. For example, both Tori and her science students connected at the city lake and were able to form deeper understandings about water quality. The kindergarten teachers helped students understand properties of water (as a solid, frozen or liquid substance) by bringing buckets of fresh snow into the classroom. As shown in the examples of the local teaching and learning experiences, studies emphasize the fact that immediate environment promotes learning at both sensory and cognitive levels. When learners gain sensory understanding, they can more readily transfer to new settings and situations. Enhanced learning occurs when students are guided by facilitators who feel a connection to the places chosen.

Also valuable is the input from those on the leadership team who do not consider themselves local, whose identity took root in other communities. In this study, Tori, Andrea and Abby critically questioned practices and beliefs that might be accepted by the others as "the norm." The ability of the "outsiders" to question what local members of the leadership team accepted implicitly has been useful to the planning team. Andrea mentions that she now uses a place-minded approach to tackle uncomfortable topics in her sociology course. She explains how understanding the ways in which the mindset and experience of her students varies from that in her own community proves useful:

Andrea (Interview II, October, 2019): Sometimes I have to think about how to state things. I have to remember that the perspective here does not match the 
perspective at home. The place where I grew up and now live is more accommodating to diversity in many ways. There is a more diverse population. There are more people who move in rather than growing their whole lives in one town. Because of the prison [a medium- security state facility], we also see more temporary residents, and that creates a difference in the school climate. Both [her home community and her work community] are considered rural, but I think there is a big difference in closed-mindedness and flexibility.

With experience and understanding, she has learned to better guide conversations about difficult subjects, and finds herself able to do so without the same sense of frustration that impeded productive talk a few years ago. To facilitate conversations about complex topics, Andrea draws on experiences in both her home and work communities.

Labeling members of the workshop leadership team as "insider" and "outsider" is overly simplistic. The notion of "insider" and "outsider" falls along a spectrum, rather than as an either/or label. While Tori is relatively new as a resident, and Andrea has commuted throughout her tenure rather than living locally, both have been in the area long enough to know generations of families, to experience major events in town, to see improvements and declines. They are not complete outsiders; rather, they have other places that serve as their main frame of reference of "home." In her first interview, Tori reflects on her own knowledge of community:

Tori (Interview I, September 2019): Where I grew up, the community was similar in terms of generational understanding. So for me, I don't know the families as well here, but I do understand the thinking. It is almost like I can trade one name for another and have the same scenario. At least a lot of times. 
Here, Tori indicates how the similarities between her hometown and the local community allow her to approach people and situations effectively, even though she is not a complete insider like others. Though she did not grow up in town, her adult life has been situated locally.

In all, the blend of local and newcomer has proven valuable during planning discussions. When working in specific places, the shared expertise has added to the collective wisdom surrounding the town, including its residents, history, and trends. This group, whether local or not, values place and its potential to impact personal and professional perspective. Each member is committed to building context, believing that doing so enhances learning.

This collective, critical awareness leads to a public better able to “...resist, critique, and imagine alternatives to the official logic...of globalization" (Donehower et al., 2007, p.10). According to their research, developing an understanding of the connection between the local and global allows learners to personally develop the literacies necessary to be global citizens while still honoring their inherent values. Teachers with a more conscious sense of place use their critical awareness to develop their own identity and support learners as they grow into global citizens. In these responses, we see the teachers using their role as concerned community members to impact their professional identities. Just as I came to this awareness, the other teachers feel a sense of duty to engage students to consider their role in the community. Andrea mentions facing difficult topics with her student rather than avoiding them. Using experience and broader understanding impacts classroom discussions and informs questioning. 


\section{Sense of Place Connects to Teachers' Expertise in Guiding Classroom Decisions}

When asked why they chose to commit to the extra time and work of the Museum Here and Now! Place-Based Workshop, responses reveal interesting and varied insights tied to professional decision making. In Tori's interview, it is apparent that she values the relevance place-based instruction brings to learning environments.

Tori (Interview II, October, 2019): I would say that I had the idea reinforced that our students are going to feel more connected to the content, whether it's science or social studies, when we can show how what they're learning in the classroom connects to their daily lives, to their communities.

Often, the awareness of community artifacts led teachers to make decisions to promote inquiry-based learning. By visiting the museum and holding period pieces such as an antique coal shovel, students felt the desire to understand and question.

For Lillian, the reason to participate takes a slightly different turn:

Lillian (Reflective Notebook, October, 2019): This is my kids' home. This is my home. This is, you know, worth our time and effort. If we don't challenge kids to question and care about this place, what will they question and care about? And where will that send us as the years go by--if no one knows or cares about the local community?

Lillian's response explaining her commitment to this work shows that she, like Tori, believes in the value of place-based instruction for student learning. Lillian's comment extends further as she mentions the long-term impact of this approach. She believes that by modeling a connection to local place, adults can create a desire in young people to share their concern and make efforts to sustain the community. The literature supports the 
practice of instilling habits of place- mindedness in young people in an effort to create lifelong patterns of practice (Clifton, 2017; Donehower et al., 2007; Percoco, 2017). When this becomes part of routine classroom practice, students develop the habit of mind to consider local impact in varied learning situations.

Drawing on a sense of the local and familiar, these teachers have implemented place-based pedagogy in classrooms with students on an increasing basis. In the beginning of the work, the efforts were activity centered. The physical place or placecentered artifact proved integral to understanding. In biology class, the use of a local leaf led to discussions of indigenous trees and how the understanding could lead to sustainable growing. In geography class, the use of historic grid maps marked the earliest efforts to lay out parameters in town. The use of artifacts served as entry points for teachers in the early stages of implementing place-based teaching. Over time, though, the teachers mentioned how place-mindedness transcends individual lessons. While artifacts are still valuable, offering a tangible quality to lesson design, there is an added layer as well that continually refers back to place and its larger connection to understanding. For Tori, something as simple as a leaf can offer a hands-on element useful during biology lessons:

Tori (Reflective Notebook, November, 2019): When the students see all learning through a local lens, they understand that these lead to bigger global connections. As a result, they think of things they are learning and how they can actually act on them and make a difference. The mindset of place and context allows discussions to take place about how lessons and units are connected, even when the topics don't make this clear. I think that thinking about place allows the students to 
connect dots in meaningful ways, and in ways we did not always know to encourage as teachers.

Instead of relying only on two-dimensional photographs in the textbook, she regularly brings in simple yet tangible artifacts to add a physical layer to lessons.

Like the middle and high school teachers, Lillian and Chelsey continue to implement place-based instruction in increasingly complex ways. While their ability to move outside the confines of the classroom is limited due to reasons related to the safety and oversight of young learners, they nonetheless talk about the ways in which their planning has changed as a result of the increased understanding of place. Lillian discusses the use of picture books:

Lillian (Interview II, October, 2019): We have always used book sets to keep the little ones interested in reading and thinking. Now, though, we do a more focused job of thinking about which books match which skills. Instead of reading a book because we've always done that in September or November, we think about the big ideas and how they tie to what is going on in their lives, in this town. So the last few years have helped us weave a common theme that relates to place and experience and we layer the skills on top of that. Lillian points out that while many elements of lesson design remain the same, their kindergarten team has aligned the books to better fit local context.

As discussed in Chapter 2, place-based instruction can be implemented in small and more comprehensive ways (Allen \& Alexander, 2013; Demarest, 2015; Percoco, 2017; Selwyn, 2010; Wilhelm \& Novak, 2011). This group experienced what is supported in broader research, that teachers who initially dabble with place-based 
practices eventually develop a deeper understanding of this pedagogical approach, leading them to implement in more significant ways as the mindset pervades their pedagogy. This ability to "start small" opened in these teachers a willingness to experiment with instructional decisions, thus enhancing existing lessons with placeminded elements. Rather than feeling a need to cast aside current instructional plans, the teachers layered place-based elements onto the parts of the lessons that were working well. The choice and control in adapting existing curriculum made early attempts to infuse place in instructional planning less daunting.

\section{Sense of Place, Supported by Inquiry-Mindedness, Builds Respectful Professional Relationships}

Inquiry has heightened the awareness of the collaborators: awareness of place, awareness of each other, awareness of the importance of place in building relationships and learning from each other. Teachers on the planning team have embraced an increased use of place-based strategies. Believing that this approach adds relevance to student learning, they have undertaken the work in a variety of ways as classroom teachers.

Tori (Interview III, October, 2019): Instead of thinking of activities tied to individual learning standards, this approach allows us to drive learning from a place of inquiry. The skills and standards can easily be integrated into what starts from curiosity.

This response indicates Tori's growth in lesson planning. Her previous approach to "cover the standards" has been replaced by course design centered around relevance and engagement. Tori's thinking is clearly indicative of how her sense of place is driven by a spirit of inquiry. 
Beyond their involvement as classroom teachers, this group has also viewed place-based work through the lens of professional development leaders. Starting with professional readings and low-stakes experimentation (i.e., quick activities in individual classrooms), this work has evolved into a collaboration to build a professional development model.

Important in the process of negotiating scenarios is the ongoing effort to build and maintain relationships. Abby, the first-year ag teacher, learned the importance of soliciting support from the community when she was a high school FFA officer. More important than the tangible sponsorships, including financial donations and goods, she learned to foster relationships within the community:

Abby (Reflective Notebook, October, 2019): Back home [Abby’s hometown], even though we were still in high school, we had to make the phone calls and invite the guests in from the community. We had a brand new building that cost half a million dollars, donated by a supporter in town, and that was when I was just coming into the program. So during my years, we were required to venture out into the community and get to know people. When we needed help with our projects, our teachers didn't arrange meetings. We did.

Abby continues to utilize her understanding of community partnerships to negotiate as Future Farmers of America (FFA) chapter advisor. Like Lillian and Chelsey, she developed place- centered understanding in her youth that continues to benefit her as an educator. For Abby, the community at the center of her work has changed. Unlike others on the leadership team, she is not working in her hometown. Still, the process of building relationships developed as a youngster continues to impact her: 
Abby (Interview II, October, 2019): When you teach ag, you have to teach so many different things. You can’t possibly be an expert at everything. Especially the first few years, when you're just trying to stay alive and make the program enjoyable enough but still teach them something. I don't know what I would do without people willing to come in and work on welding projects or greenhouse sales. People who know a lot more than I do about these things. I just try to watch and learn.

Abby's insights reveal her reliance on community support. Place-based pedagogy is recognized as a collaboration among learners, including students, adults, and community members. Rather than rigid roles, these groups function together as co-learners in an environment of inquiry in which students and teachers pursue their own areas of questions and curiosities as the teacher helps guide and connect to discipline and curriculum expectations. One example of the importance of inquiry involves a failing flower garden. Following repeated attempts to make the area thrive, students reached out to a partner at the Department of Conservation for help. The result was a source of pride for the students and teacher, and a model of collaborative problem solving. Teachers in this study grew in their understanding of shaping learning led by questions rather than predetermined curriculum and standards. Adults and student functioned as co-learners in this example and others. They used the local context to identify needs and opportunities; learning resulted as they worked together to increase their collective understanding of local situations, including the people, places, and authentic scenarios.

The collaborative nature of place-based work is equally important in the professional development planning stage. For the leaders involved in designing 
professional development around the topic of place-based pedagogy, a team approach is vital as this study confirms. Tori indicates a different facet of the relationshipcenteredness of place-based pedagogy:

Tori (Interview III, October, 2019): We have practiced thinking together about what observations they can make in the local area and from that they can begin to develop concerns related to the environment or the culture. We ask each other to think about things that have happened in the area in the past and recently and what personal connections we all have, in other words, why these events or occurrences stick in our minds. From there, we can think about mapping the concerns to try to uncover patterns that could lead to global connections and recurring concerns.

While Abby emphasizes the use of trade experts as partners, Tori suggests that an internal partnership among the leadership team is equally vital. This group has learned to constantly communicate through inquiry to identify authentic topics. By generating questions tied to local needs, participants noted the value that the place-based professional development has brought to their teaching. Through inquiry and communication, the leadership team has grown to understand the importance of building community relationships.

\section{Professional Relationships in Place-Based Work Expand Beyond Educator Circles}

The Century Farm project features still a different aspect of the relationshipcenteredness of place-based learning. This work involves an indigenous planting project on a local Century Farm (meaning the farm has been continuously owned by the same family for at least one hundred years). The key players in this work include educators on 
the leadership team as well as two community members, including a Missouri Department of Conservation official and the Century Farm owners, whose relationship extends back six years to the start of the indigenous planting project. This work began as they made efforts to improve environmental sustainability on the farm. What started as an environmental sustainability project has expanded to include educational impacts too. The participating teachers have visited the now mature plantings (trees and fence hedge) in order to discuss the science behind the project.

Tori explains how this real-world project has influenced her science classroom:

Tori (Reflective Notebook, October, 2019): For my biology course planning, this is as real as it gets. Teachers in situations like these are learning about work that was done based on genuine need and incorporating that into conversations and lesson design.

Through site visits or even pictures and video, classes can see that in life, the need to collaborate exists. Adults can't thrive in a bubble. And in rural areas, people are more known to one another. Numbers are smaller and relationships form on several levels. You might know someone from booster club or church and that makes contacting him for reasons like this that much easier. If teachers can guide students to understand how to build relationships, they will carry this ability forward and apply it later.

Andrea too speaks of the relevance brought to learning through this practice of drawing professional expertise into collaborative planning:

Andrea (Interview III, October, 2019): I don't teach science, don't claim to know much about the life cycles happening along the fence. But I do know that if you compare this work to other kinds of community partnership, say mock trials when 
students role play before an informed audience, this feels more meaningful, more authentic. Kids know when you are playing school, and this work shows them the realities of multiple stakeholders.

Seeing and carefully observing the collaboration among community members in projects like the cycles of indigenous plantings allows students to grasp the different skills brought to the project. For the historian/land owner, historic photographs provide a glimpse of the way areas on the farm looked decades ago. The conservation expert uses these and determines what plantings will thrive. The farmer who leases the space can contribute thoughts about possible disruptions to his work that new plantings could cause. Together, the collaborators on the project have built a plan that benefits everyone and values the collective wisdom of the group through ongoing conversations. It is not an instructional approach teachers can fully adopt without the investment of time and relationships.

The work of designing and planting areas on the farm is significant. This project limited soil erosion, brought pollinating butterflies back in larger numbers, and resulted in planting a section of trees that will soon provide a wind break for grazing livestock. But the science learned is only half of the picture. Equally important, and rounding out the scene, is the critical thinking that occurs when projects like this are used in lesson design. By collaborating with English Language Arts (ELA) experts, lessons drawing on partnerships like this take on an added layer of critical inquiry. By stepping back to analyze the reasons behind the work and the timing, teachers can learn to guide students in inquiry-centered reflection. Ultimately, this kind of work allows learners to feel confident tackling new issues through a process designed to ask and address thoughtful 
questions. Similar partnerships have resulted from the work with other members of the team. While the actual work varies, uniting each project is the level of trust built through the sustained relationships.

Like the planting project, the kindergarten teachers have engaged multiple community stakeholders in work that shows that even the youngest students can benefit from an understanding of shared wisdom. Lillian and Chelsey have, for some years, taught everything from winter safety to measurements to kindergarteners through a "Gingerbread Escape” program just before winter break. Each year, after decorating gingerbread cookies, the class heads off to lunch, planning to return and eat the cookies for dessert. Instead, the kindergarteners return to find the room turned upside down and the gingerbread men missing. Through the week, the class puts together clues, many of which are provided by visiting community members who have spotted the cookies on the loose.

\section{Figure 2}

\section{Highway Patrolman Participates in Kindergarten Gingerbread Escape Program}

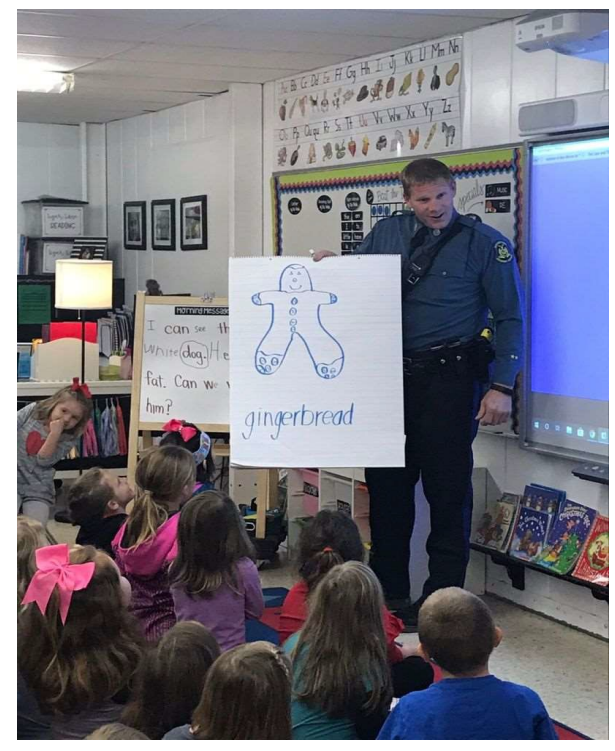

Photo courtesy of school and officer permission. 


\section{Figure 3}

Kindergarten Students Visit Local Radio Station as Part of Gingerbread Escape Program

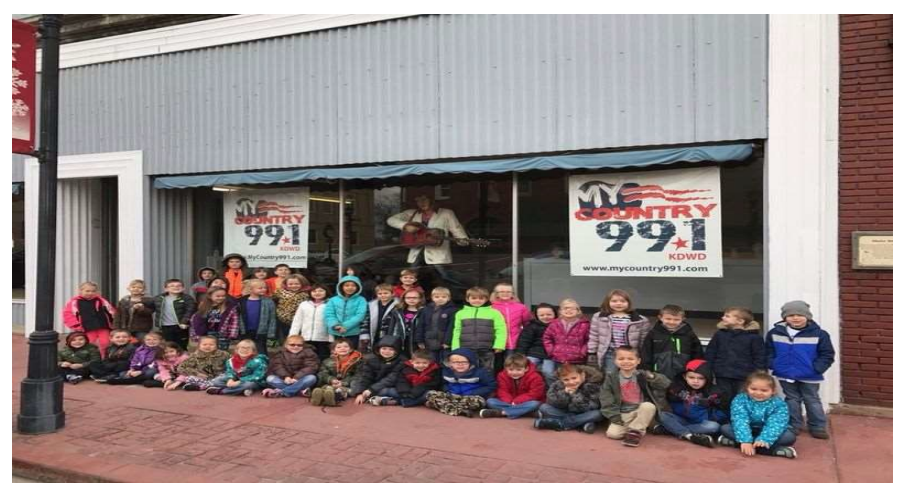

Photo publicly available courtesy of school website.

Lillian reflects on how the use of community members enriches this project and promotes learning for the kindergarteners:

Lillian (Reflective Notebook, October, 2019): The gingerbread project, though a lot of work for the adults involved, is such a fun time for the kids. While searching for the missing cookies, they hear from experts in several fields, including law enforcement and culinary arts. A scenario we create keeps them engaged. They practice writing and remembering details. The addition of a radio station visit this year made for a busy morning, but was so well received by the town and the kids. Each student described his or her cookie live on the air. While we hear from different experts each time we try this, we have improved our understanding of how to teach skills through the work. We used to think of the gingerbread project as a fun before-break activity. Now, it is truly the best job shadowing we do. The students learn about the town, and often its history. On the flip side, many of the adults get a glimpse into the school in ways that bring them 
past the front office.

In becoming more place-conscious, in this learning experience and others, Lillian and Chelsey make adjustments. They use local narrative in describing the cooking sightings, drawing on historic events that happened in locations where the cookies are "spotted" such as building histories. They call on professionals from the community to visit in official capacities, rather than only calling on students' families. Students now describe with words and pictures descriptions of the "missing" cookies. The class describes and tracks the weather forecast on days the cookies are "on the loose." Again, we see teachers engaging students with topics of local interest. While it seems simple to create a mock cookie escape, young learners are using questions and clues to fuel interdisciplinary study. The teachers are constantly considering adaptations to this activity and others. As discussed in Chapter 4, play centers are now enhanced with local relevance (e.g., Restaurant Week in the Kitchen Center, local farmers in the Market Center, etc.) Hands-on, imaginative play has long been used in kindergarten; now, the teachers are constantly thinking about local ties to concepts.

A quick glance at the work happening in the kindergarten classrooms might cause one to overlook the parallels in other place-based collaborations. Upon closer reflection, the similarities stand out. Whether the topic is planting, welding, or gingerbread safety, successful outcomes depend on the ability to ask the right questions, develop a timeline, and determine what community partners would best carry out the project. The disciplinary expertise of content teachers and field experts combines with the communication expertise of ELA teachers to guide thinking that leads to a collaboration that utilizes the collective expertise of the group. What results is interdisciplinary 
learning guided by authentic purpose. The literacy research supports interdisciplinary collaboration that values the unique ways that content and trade experts know how to read, write and think critically, and how those approaches vary within disciplines (Allen \& Alexander, 2013; Beck, 2005; Brandt \& Clinton, 2002; Buehl, 2014; Hill, 2014; Jetton \& Shanahan, 2012; Lesh, 2011; Lesley, 2014; Selwyn, 2010; Street, 1984; Wilhelm \& Novak, 2011). Examples from this study point to the fact that learning is enriched by the collaboration among experts from varied backgrounds.

\section{Sense of Place has Led to Deep and Enduring Professional Growth in Teachers}

Just as a developing sense of place has impacted the team's personal and professional identities in both subtle and conscious ways, becoming more placeconscious has also helped the teachers better contextualize instruction. For the leaders of this place-based work, those interviewed for this study, place has become a building block upon which instruction stands.

While the examples of instructional activities discussed below vary widely in many ways, a common thread of place extends through them. And through interview responses and reflection, it is clear that implementation of place-minded instruction has resulted in lasting growth and change in teachers. Chelsey contrasts this kind of questiondriven collaboration with more typical professional collaboration that comes from conference attendance:

Chelsey (Interview III, October, 2019): We usually attend the kindergarten conference. And there are good things to be learned there. This was especially true when we were new and learning. Now, though, it is nice to have an interactive discussion instead of "sit and get." Don't get me wrong, we have 
formed some relationships over the years. But now if we need something, we know who to call. Too often, we get into a session and feel that we know the topic better than the presenter. And then the stress of being gone with a sub hits and it just doesn't seem worthwhile. This work with the team has taught me more than any meeting I've attended. Definitely.

Tori echoes the value of professional collaboration in place of "sit and get" professional development, in which teachers passively attend workshop sessions and collect materials for use in their classrooms.

Tori (Reflective Notebook, November, 2019): Not just this work, but the range of Writing Project work has really helped me think differently as a teacher and a professional. It is weird to say that my best PD is not coming from a science group. I feel valued now as the person bringing science expertise, but for me the value has been in growing in my ability to ask good questions and solicit responses from the students that don't boil down to a single right answer. I am a better teacher of thinkers now.

It seems clear that the professional collaboration that has grown in this group has resulted in them feeling like they are in control of the direction, rather than waiting for a directive from someone else. Over time, the planning that has taken place has evolved based on classroom trial and through continued inquiry-driven reading and studying. Andrea reflects on the ways the place-based work has been valuable in encouraging professional growth:

Andrea (Reflective Notebook, November, 2019): The value for me has not been to learn about place for place's sake, but because structuring learning from 
questions offers students a richer experience. Sure, I've learned a lot about the locations we use in this work, and about the town in general. But what really matters is that I am better at asking students to read and respond. There is so much less chapter work and vocabulary work for its own sake. Now, these activities are part of a bigger, more meaningful whole.

Andrea reveals improved confidence in her ability to question and engage students. Here we see a strong example of a teacher supporting student inquiry as learning extends beyond a classroom and a textbook.

In rural areas, realities of place can be isolating. Schools often employ a single content expert that limits the professional collaboration that would exist in larger places. The structure of the place-based professional development offers educators the opportunity to build relationships that extend beyond the workshop dates and provide a chance for ongoing professional dialogue to take place. In addition to the connections built among educators are the relationships formed in communities as a result of the work. Tori speaks to the lasting professional growth encouraged by the place-based work: Tori (Interview III, October, 2019): I now work with science teachers in a number of schools. We all have certain strengths; our schools have certain restrictions. But together, we can usually work toward resolution. Just this week, I helped a colleague work out a scoring guide that managed to do the work we needed in disciplinary literacy as far as science writing and still satisfy the district requirements. That is something I would not have felt comfortable talking about three years ago.

The collaboration among the group of professionals has led to enduring professional 
relationships. Elements of literacy infused into the planning are enriched by the interdisciplinary expertise of program leaders. Because activities have been tied to place, the group has sought readings that draw upon expertise of multiple content areas. As the group has gotten better acquainted, they have learned how to draw upon individual strengths of the group in program planning.

The experience of the leadership team with regard to gradual increase of placebased implementation aligns with understandings gained in other research contexts (Brooke, 2003; Demarest, 2011; Deringer, 2017), in which teachers, ranging from beginner to expert in terms of place-based implementation, are positioned along a continuum. For some, an existing lesson is enhanced with a nature walk; on the opposite side of the spectrum, other teachers are guiding full inquiry-driven place-based units.

Just as a sense of place has impacted the team's personal and professional perspectives in a variety of ways, becoming more place-conscious has helped the teachers make learning more relevant. Beyond showcasing the physical location, this group of teachers has come to regard place as a block upon which to build instruction.

Through this collaborative work, the teachers have become more mindful of place when planning instruction and collaborating with colleagues in ways that lead to enduring shifts in practice. Even when learning happens inside the confines of the school, their comments reflect a stronger interest in grounding instruction within local context. The research suggests that by doing so, students develop immediate understandings that broaden to more distant contexts (Allen \& Alexander, 2013; Brandt \& Clinton, 2002; Brooke, 2003; Clifton, 2017; Demarest, 2011; Flower, 2008; Lesh, 2011).

In the professional development, teachers grew as they learned about content and 
teaching from colleagues across disciplines and grade levels, as explained by Tori in the final focus group meeting:

Tori (Final Group Panel, November, 2019): This work mixes with other PD I've done. It extends beyond science and improves my confidence in tailoring instruction to meet needs. I was confident ten years ago about science. It is the rest of teaching that this project helps me consider.

For Tori, the place-based professional development has led to increased confidence in the many parts of teaching that fall outside of content expertise. Andrea's response echoes this belief that place-based professional development supports teachers' growth:

Andrea (Final Group Panel, November, 2019): I agree. When I stop and think about the things we've tried and changed and all the ways we've learned, I appreciate the fact that this project has made me grow. Even when I complain that it takes me outside my comfort zone, I know it's good for me.

The wider research on place-based professional development often emphasizes aspects of inquiry, collaboration or disciplinary/literacy expertise. The literature supports the fact that these qualities appear in viable place-based instructional approaches. In this study, we see that teachers grew over time in their understanding of how these components (collaboration, inquiry, and disciplinary/literacy expertise) intertwine to lead to meaningful learning. As professional development planners, the team has come to understand that only by giving conscious attention to the intermingling of these elements can this professional learning experience achieve its full potential.

For Tori, the work has led to increased understanding of the many aspects of teaching that fall outside the boundary of content expertise and instead relate to the similar 
challenges teachers face no matter their grade level or content area:

Tori (Final Group Panel, November, 2019): This work has taught me so much about what other people do. I always thought of kindergarten as a completely different world. Now I see that there is so much benefit to thinking through things together. What they do in stations can help us be better with older students. We all get stuck in our ruts, and this work has really provided opportunity for meaningful conversation.

In this instance, Tori's professional growth was not centered around content, but around gaining expertise as for managing a high school classroom. Tori learned that to grow instructionally, she needed to consider the broader spectrum of teaching beyond her content area.

The ways in which kindergarten teachers structure learning through play naturally integrates reading, math, science, and history. Place-based learning came naturally to the kindergarten teachers. The use of context and place was already integrated into their learning processes. For the teachers of older grades, as Andrea demonstrates below, thinking about learning through place offered a reminder of how important it is for teachers to build context into lesson design:

Andrea (Final Group Panel, November, 2019): The museum partnership has reminded me to think outside the textbook and outside the classroom walls. Instead of pushing my way through chapters chronologically, I remember to think about the reading and writing that might make students think. I try to always think about what expert I can bring in or what relevant current event might ground the learning. 
This work helped teachers of older grades become more aware of the importance of context in lesson design. It further allowed professional growth through collaboration; what kindergarten teachers were doing already, the high school teachers adapted. The practice of cross-grade and cross-disciplinary sharing helped the teachers gain insight into the thinking of their peers. Many professional development experiences focus on a particular content or outcome. This work prioritizes deep professional conversations key to enduring growth and collaboration.

These members of the leadership team have been thinking about and implementing place-based pedagogy in a variety of ways. The following lesson excerpts show the original elements of the water quality test at a local site. Through this work high school biology students learned to test water on the basis of water temperature, turbidity, dissolved oxygen, and $\mathrm{pH}$ level. The materials shared below demonstrate how the group learned to take a sample and conduct the test in order to write a report of the findings.

\section{Figure 4}

Slide from Original Lesson

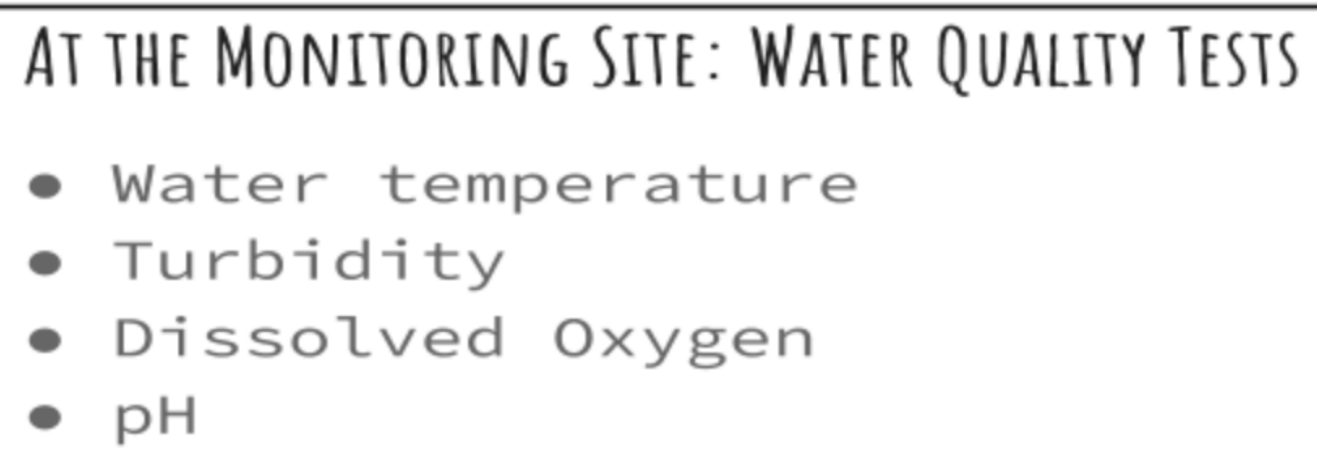




\section{Figure 5}

Revised Lesson Materials Showing Added Components of Inquiry and Sketchnoting

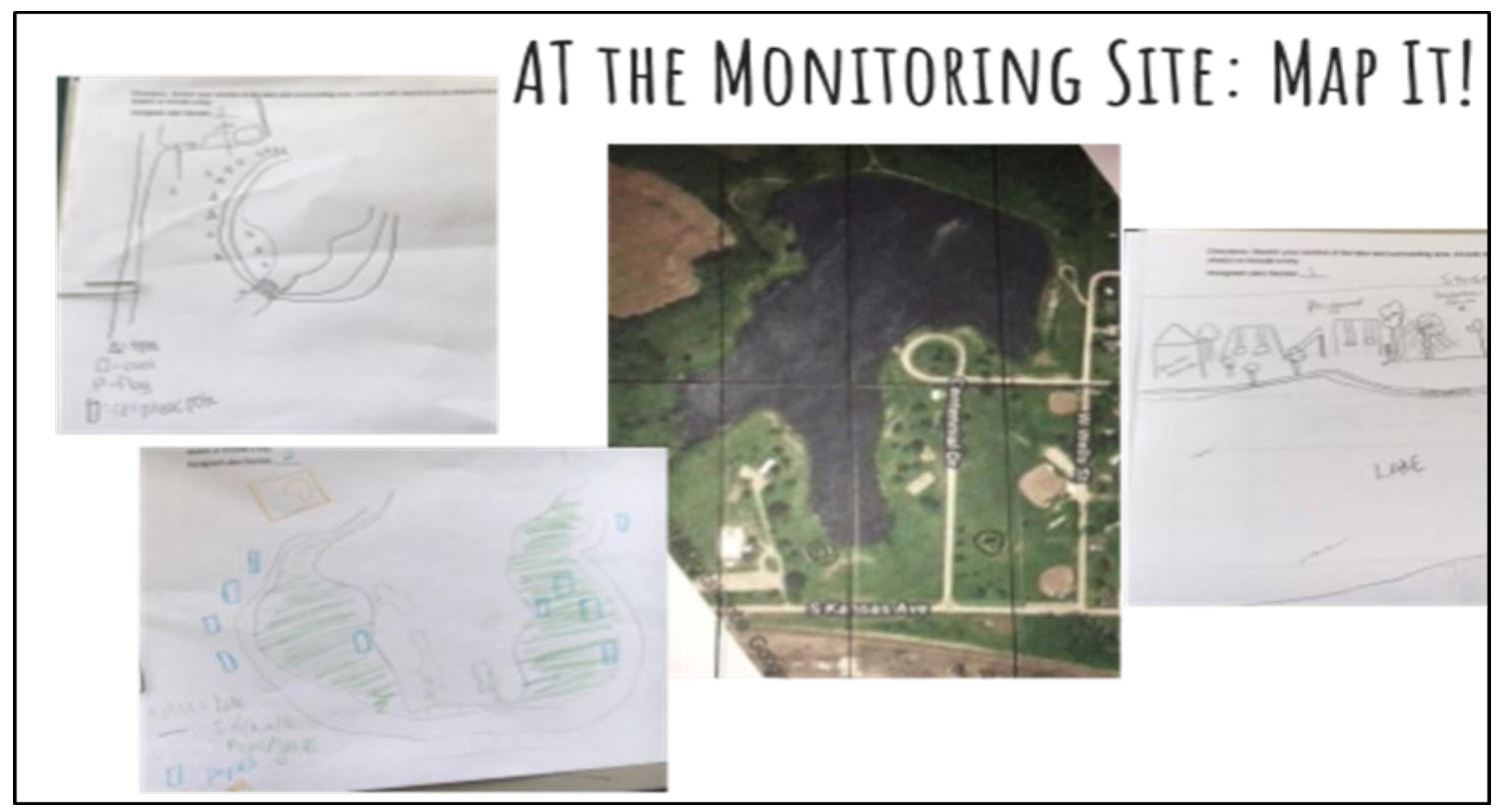

In the revised version of the lesson, it is clear to see some added interdisciplinary aspects. On the left are student samples of a mapping activity, bringing in social studies skills that include studying the topography of the area as well as scaling. Also evident are the questions used to guide the inquiry. Using these broad questions, students engaged in critical thinking exercises such as predicting and reflecting.

The comparison of these early and revised lesson elements reveals increased understanding in the integration of content areas. What started as a single-day activity evolved into learning that was part of a greater whole. The students participating in the early lesson learned about $\mathrm{pH}$ levels, a measurement indicating the degree to which solutions are basic or acidic. The original plan was to test $\mathrm{pH}$ levels at a number of local water sources, including the city lake. The original slide shows content being delivered in lecture form to conduct a test. Students, and later teachers in the profession development, visited the city lake and experienced hands-on learning about water quality. 
Once revised, the lesson expanded in significant ways. While $\mathrm{pH}$ level was still tested, this understanding became part of a greater discussion of sustainability. Along with testing water quality on a local century farm, the lesson calls for participants to think about sustainability more broadly than just the inherent science. Through notebooking activities, they practiced careful observation and reflection. With the help of the social studies teachers, they traced land ownership through the use of historic and current plat maps. The revised lesson also includes the testing of $\mathrm{pH}$ level, but extends its objectives to include sketchnoting and labeling. The lesson sequence included a greater discussion of sustainability. Along with water quality testing on a local century farm, the revised learning experience asked learners to practice careful observation and reflection. Local land ownership was traced through the study of historic plat maps. In all, the lesson evolved to encompass a deep understanding of a piece of land--its physical features and how these changed over time, its economic impact, and its ongoing narrative (only part of which is represented through a study of recorded history).

Evident too is the increasingly open-ended nature of student response. While the early lesson builds toward an understanding of concepts, the revised version shows growth in teacher understanding of content and process. In both cases, the student would need to grasp the concept of PH level or topography, for example. In the revised lesson, though, these concepts are built into an inquiry around protection of resources. By thinking about the best pedagogical practices surrounding inquiry-driven collaboration that relies on disciplinary/literacy expertise, this team has developed their skill to look at place-centered learning experiences as interdisciplinary rather than discretely tied to a single content. This team has learned to apply the best-known disciplinary/literacy 
practices to create inquiry-driven, interdisciplinary learning opportunities, the types of experiences modeled in literature (Beers \& Probst, 2017; Jetton \& Shanahan, 2012; Percoco, 2017).

As research on effective professional development reinforces, professional learning occurs most notably when teacher expertise is honored. With place-based pedagogy, teachers are constantly making adjustments and decisions to bring relevance to learning. What started as Tori's water quality lesson became an inquiry-driven, collaborative instructional approach calling on disciplinary/literacy expertise. The teachers adapted to changing circumstances.

Ultimately, responses indicated that participants were engaged by the place-based work. Their implementation took many forms and has evolved over the course of the project since we first took on the work. As you can see, place-based pedagogy falls along a spectrum, from experimental to full implementation. As teachers grow more comfortable, they allow learning to become more student-driven. Ultimately, interdisciplinary inquiry, the kind of learning championed by Dewey, is the goal. The experience of this team of teachers aligns with the goal of place-based pedagogy as defined by Smith when he describes it as pursuing local questions, critiquing local truths, developing local partnerships with individuals and organizations, and studying in local surroundings so that learners develop deeper understandings that promote their growth as students and thoughtful citizens (Smith, 2002).

\section{Conclusion}

The results of the study track the progression of a team of teachers engaging in place-based pedagogy as both classroom teachers and professional development planners. 
Their interview responses reveal that the teachers have grown more place conscious as a result of their work on the leadership team. This has happened over time, as they studied professional readings, experimented in their classrooms with place-centered activities, and engaged in ongoing professional conversations. The increased awareness of place has led to shifts in the teachers' pedagogical outlooks. The shifts have allowed the enriched place awareness to fuel growth in guiding student inquiry, since the work is grounded in developing understanding based on context. This group of teachers has experienced individual and collective breakthroughs in understanding that transcend content area, grade level, and even school boundaries.

While I have separated Chapter 4 into four findings, the reality is that these results are overlapping and intertwined. Finding one, emphasizing the fact that sense of place impacts personal and professional identity, underscores each of the other findings. The professional collaboration and decision making emphasized in the findings ultimately led to professional growth in these teachers. There is value in discussing each finding, but it is also important to note that ultimately, the overall professional growth in each leadership team member marks this work as a success. In this study, success is defined as the growth demonstrated by their ability to use place in making professional decisions through planning, instruction and collaborative reflection. Further, what distinguishes this study is the experience and growth shared by this group of educators as they designed and implemented a sustained professional development model.

In Chapter 4, I have used the design study approach in reporting findings of the leadership team. As guided by Reinking and Bradley (2008), it is hoped that understandings gained by this team could be applied elsewhere, with other teams in other 
places looking to improve place-based instruction. Because design studies are not meant to be strictly replicated, but instead to help teachers adapt their practice, the work experienced by this team at this museum could be adapted to fit other communities with strengths and partnerships personalized to them. It is this "methodological flexibility" based on the unique learning needs of the situation that makes design study an effective approach for this work (Reinking \& Bradley, 2008).

As discussed in Chapter 2, I approach this study from a sociocultural perspective, and a constructivist paradigm, believing that physical environment and social interaction have a profound effect on learning. The work of Vygotsky (1986) and Gee (2004) promotes the idea that language is meant to be primarily social rather than internal. This thinking is key to place-based work given the reliance on relationships and collaboration. Ultimately, it is the relationships that matter, the relationships between teachers and students, between teachers and other teachers, and between both students and teachers and community stakeholders. If we can encourage all learners, whether students or adults, to acknowledge shifting/multiple truths, to ask good questions, and to show respect to themselves and others, they will transfer important habits of mind even as their community affiliation shifts. Knowing how to interact with and treat one another is the foundation of this important work.

The findings in this study echo larger studies of place-based pedagogy. Of particular relevance are Austin (2015), Brooke (2003), Demarest (2011) and Sobel (2013), whose overviews of place-based pedagogy provided a frame of reference for the local team of educators as they first undertook this work. The practitioners described in the literature provide useful rationales for the relevance and engagement offered through 
place-based learning, showcase models of effective community partnerships, and emphasize the ways in which teachers can undertake the work gradually. Ultimately, it comes down to Lillian's observation during Interview I: "if you are human, place matters." 


\section{Chapter 5}

The purpose of this study was to examine the perceptions in a team of teachers as they worked to design and implement place-based professional development informed by classroom experience. With underlying roots in the work of Dewey (1938) and Vygotsky (1986), the focus of place-based pedagogy is that grounding instruction in local contexts adds relevance and supports engagement for learners.

As outlined in Chapter 2, several factors define place-based pedagogy. This approach to teaching is collaborative, inquiry driven and disciplinary/literacy centered (Austin, 2015; Brooke, 2003; Demarest, 2015; Sobel, 2013). The interest-driven contextualized nature of place-based pedagogy supports the practice of building in students an increased critical consciousness resulting in their becoming citizens who value community (Clifton, 2017; Deringer, 2017; Donehower et al., 2007). In addition to benefiting the common good is the belief that place-based instruction helps individual learners, offering relevance and context to learning environments.

Based on the design study approach of Reinking and Bradley (2008), this research used theory to inform ongoing practice (Cobb, et al., 2015; Darling- Hammond et al., 2009; Lampert et al., 2010). Design studies seek to inform practitioners through a relatively broad generalization of findings not specific to a sample population (Reinking

\& Bradley, 2008, p. 23). It is hoped that understandings gained by this team of educators could be applied elsewhere, with other teams in other places seeking to implement or improve place-based instruction. Because design studies are meant to be adapted rather than strictly replicated, they offer a structure for teachers to layer new understanding onto existing knowledge while reaching beyond a single classroom. As discussed in Chapter 3, 
design studies merge these often-separated spheres, considering both "why" of research and "how" of practice.

\section{Summary of Findings}

The following research questions were used to guide the study and capture how participant perspectives surrounding the idea of place took shape: How does sense of place impact teachers? How does place impact their professional identities, classroom decisions, and professional relationships? Below is a summary of the four main findings that the research identified.

\section{Sense of Place is Integral to Sense of Self, Becoming Part of Personal and Professional Identity}

Through the place-based work, the participants in this study have become more place- conscious in their personal and professional lives. Ongoing experiences with place-centered activities has led to the practice of being more place-minded. The group now uses both an individual and collective sense of place in professional discussions and planning. This linking of place and identity is fundamental to the work and is woven seamlessly throughout the other findings. The group's attachment to place did not happen as a result of the work, since humans naturally feel these ties. The conscious use of place in collaboration and planning, though, reflects a heightened awareness in using place more productively.

\section{Sense of Place Connects to Teachers' Expertise in Guiding Classroom Decisions}

From early efforts to fuse place into lesson planning by drawing on a sense of the local and familiar, these teachers have implemented place-based pedagogy in classrooms with students on an increasing basis. Beginning with the early stages of implementation, 
in which the teachers used artifacts as entry points, to more comprehensive ways of thinking about place, the teachers have evolved in their understanding of how place can provide an access point for students in making learning materials engaging and relevant.

\section{Sense of Place, Supported by Inquiry-Mindedness, Builds Respectful Professional Relationships}

The place-based work has challenged the leadership team to build and maintain professional relationships in meaningful and sustained ways. Both internally, as a collaborative leadership team, and in reaching outside the team to forge community partnerships, collaboration has been a main component in this project. The inquiry-driven nature of the work means that, like other parts of the planning, ongoing and adaptive decisions regarding collaboration occur as the team considers the most relevant stakeholders.

\section{Sense of Place has Led to Deep and Enduring Professional Growth in Teachers}

For the leaders of this project, place has become a fundamental consideration in designing curriculum. The teachers have used place as a building block in designing classroom curriculum and when making choices regarding professional development for colleagues. Their reflections make clear that the implementation of place-minded instruction has resulted in lasting growth and change in teachers. As the team has studied place-based pedagogy, the following list has emerged as they have prioritized the elements that they believe support effective professional development: includes active learning, includes content focus, feels coherent to student and teachers, is sustained over time, and invites collective participation. This teachers teaching teachers model is iterative and flexible in nature. The workshop, as a result, is increasingly 
interdisciplinary, inquiry-driven and collaborative.

\section{Implications and Recommendations for Implementation}

For the purposes of discussion, I have delineated the findings and resulting implications into four categories. But the truth is that the underlying notion of place is interwoven throughout all findings and implications. Discussing basic identity, as in the first finding, naturally extends to the other findings. Talking about lasting professional growth includes disciplinary expertise. As the team collaborates, new partnerships are formed. The swirl of gradual development is both the value and the challenge in placebased pedagogy, or, as Dobbs et al. (2017) note, it is its "messiness" that eventually leads to valuable professional growth.

The implications result from participant reflections following three years of work on the professional development leadership team. Their collective thinking encourages educators who are considering a shift to place-based pedagogy to start small rather than taking on the work in a way that could overwhelm them. The shift to place-mindedness in teaching should not feel abrupt or sudden, but gradual. By enhancing existing curriculum and effective practices with an increased understanding of local context, teachers learn to welcome rather than resist an environment that supports uncertainty and questioning. The findings also emphasize the importance of building partnerships with other educators and with community stakeholders. Throughout this process, the growth in the teachers happened through purposeful collaboration.

\section{Start Small}

As they first attempted to study and use place-based practices, the leadership team was mindful to take on manageable parts of the work. For them, the use of place-minded 
routines and strategies was voluntary. Teachers infused small, place-based elements into their instruction and sustained that work over time. The group chose to implement in incremental stages while their understanding and experience grew. As they experimented in their classrooms, the team continued to engage in professional conversations and considered how they could most effectively create a professional development experience.

Place-based pedagogy can seem overwhelming. For those who believe in its merits, it is important to simply get started. This can happen by testing it out in small ways such as working in a brief activity or extension of an existing lesson that pertains to place. Many opportunities exist to plant the seed of place-mindedness:

- Use relevant texts tied to place. Allow students to see the region through print and film resources in a variety of genres.

- Explore accessible physical spaces. Take advantage of nearby natural or historic spaces. Remember that ordinary destinations can be charged with place-based opportunity (e.g., a simple natural feature in a nearby park or a long-forgotten coal chute).

- Use artifacts and photos (singularly or in collections) in order to provide students with a hands-on sensory tied to place. Both historic and current versions of artifacts can compel students to think in new ways.

For some teachers, local factors can impact use of place in instruction. For example, district curriculum guidelines or the location of a school campus can limit access for teachers wishing to incorporate place in lesson design. While issues of time and physical access are valid, place-mindedness is not an all-or-nothing venture. Small, 
manageable options exist for layering place-mindedness into instruction. Using regional texts, locating relevant artifacts, and moving outside the classroom can impact learning in ways the students find memorable and engaging.

In our group, the science teacher takes high school students on short walks across campus. In one such case, she ventures just beyond the football field, where an historic tree provides an opportunity to discuss dating for physical science students. Similarly, the agriculture teacher offers a walking tour of campus each spring for her ag structures class to showcase previous projects. The kindergarten teachers bring buckets of snow into their classes following the first snowfall of each school year, which the students use to study and then make snow ice cream. When implementing place-based pedagogy, teachers should feel that starting small is a necessary first step.

\section{Build Partnerships In and Out of School}

Relationship building is perhaps the most important understanding for teachers wishing to gravitate toward place-mindedness. As discussed in Chapter 2, school projects are too often decontextualized and detached from the lived realities of students. Learners can feel an unnatural separation between their lives in and out of school.

The value in place-based pedagogy comes from believing in the importance of school and community engagement. Effective inquiry occurs when students undertake authentic learning opportunities facilitated by place-minded teachers. In order to begin the shift toward using school and community relationships to support learning, teachers can think in the following ways:

- Begin with local colleagues. Review which teachers also instruct your students.

- Consider common topics and then work with that colleague to design collaborative, 
place-centered activities.

- Reach outside your school and work with neighboring colleagues. This work can be an effective way to partner with area educators. In our virtual age, collaboration among students and professional colleagues can occur in new and exciting ways. The option to hold virtual meetings offers an added opportunity to engage in learning.

- Think about recurring events in your community. Work with organizers to include students in the planning and implementation phases. Most community leaders welcome the opportunity to volunteer alongside students.

- Consider local challenges and opportunities. Reach out to the main stakeholders to discover ways that local youth can contribute to ongoing conversations. Remember that in cases of emotionally charged topics, it might take more than one attempt to engage with local leaders. As a level of trust builds, so will the access.

This approach to learning values the professional expertise of the entire learning community, including educators, community members and students. Collaboration among these groups is a fundamental part of planning and implementation for placeminded teachers, present in each phase of the work.

Setting out, I knew my interest in connecting place and learning for teachers and their students. What I came to understand was that by gaining awareness of place, teachers grew professionally in ways that extend beyond content knowledge or literacy skills. Several of the responses in Chapter 4 speak to the impact this work has had on the team's professional identities that will, in turn, further impact their classroom decisions and collegial relationships. Because they have been challenged to collaborate for extended amounts of time with a mix of educational colleagues and community members, 
they have grown to embrace the opportunity to co-plan and co-create. Moving forward, this interest in place as the foundation for instructional planning is significant. Place has become a pillar for this team in teaching and planning professional development because the group now understands how to ground learning in context. Beyond that, members of the team welcome the opportunity to form new partnerships and design learning as it unfolds rather than feeling as though all planning has to take place in advance of the experience. In thinking about the "messiness" of place-based instruction, viewing uncertainty as a strength rather than a concern allows the team to function more confidently as collaborators.

This work has impacted the professional identity of each team member. Also noteworthy is the collective identity they have formed as a group. In the early stages, some perceptions existed about limitations the teachers felt. Kindergarten teachers hesitated to offer input to colleagues teaching more advanced levels of science and social studies. High school teachers marveled at the descriptions by kindergarten colleagues about the level of planning necessary to manage behavior and movement in a kindergarten classroom. Content area teachers questioned whether they had the expertise to teach reading and writing. Though consistently professional and kind, there was trepidation based on content area and grade level that existed in the early stages of this work. Over the three years the group has met, these lines have faded. They now rely on one another to think through challenges when planning professional development for colleagues. In addition to growing more comfortable with uncertainty as classroom teachers, the group has taken a more relaxed stance in coming to group decisions. The discussion that circulates around programming topics is much richer as the group grows 
more willing to question one another.

\section{Fuse Place-Based Pedagogical Practices with Existing Instruction/Curriculum}

As educators first attempt place-based practices, it is important to remember that this instructional approach is an added layer rather than an abrupt shift. Teachers should continue using existing instructional materials. Instead of replacing units of study, they should consider how to supplement current curriculum with local place-based elements. By layering local narrative (speakers, photographs, and other artifacts), teachers can ground existing curriculum in relevant local context.

This group has found versatile ways to integrate new elements into the existing curriculum. In kindergarten, Lillian and Chelsey have implemented local elements into their learning stations. The kitchen is transformed to look like a local eatery during Restaurant Month each January, and students illustrate menus as a thank-you tribute. In the fall, local farmers donate locally raised produce for students to use while playing in the kitchen. These small shifts pull in local relevance for kindergarteners learning about food sources. Learning targets are met as elements of the local environment are pulled in to reinforce concepts. Too often, an unnatural separation exists between school and life. Small adjustments to the existing curriculum can positively impact learning.

In the upper grades, teachers are currently working to develop a "trunk show" to support the annual ninth grade Museum visit. Two weeks prior to this event, all freshmen participate in a guided tour of the Museum offered to support their study of American Industrialization. The science, ELA and history instructors (all part of the leadership team) have created a collection of artifacts intended to activate prior knowledge, inquire about family ties to mining, and increase engagement throughout the unit. This "trunk 
show" includes tools from the industrial era, readings from period newspapers, and articles of clothing. While sometimes "trunk shows" replace student access to museums, this one works as a preview to the visit. By writing about, thinking about, and making predictions about the use of the artifacts, student thinking is activated as they begin the unit of study. The hope is that this preview will lead to stronger engagement on the day of the actual visit. Students are challenged to notice personal and historic ties to place, to question current and previous practices, and to understand local industry. The content knowledge of educators and trade experts is utilized to challenge students to form questions in order to connect their understanding.

Across all grades, the previously mentioned use of related texts is another example of how teachers can slowly implement place-based instructional practices. As discussed in Chapter 4, Lillian and Chelsey have reorganized their use of picture books to better coincide with units of study that emphasize the region. As supported in broader research, picture books have proven to be a valuable resource. Brief and engaging, they prove useful even in planning for olderstudents. Along with narrative pieces, the local team finds that historic archives offer an additional way to ground topics locally. Local history books and newspaper archives can challenge students to consider the impact of historic events, people, and places. Place-based pedagogy is a way for professional expertise to be honored and valued. Teachers can feel confident in the decisions they make as they navigate place-minded instruction for their students.

\section{Build Stamina for Teacher Uncertainty in Student-Led Inquiry}

In creating an environment of inquiry, teachers face the obstacle of shifting students' previous experience. Typical schooling is teacher directed. Students are often 
required to follow directions and answer questions developed by teachers. Inquiry is yet another mindset shift required in place-based models, as students actively generate the questions and thinking that drive learning.

Typical curriculum is designed to "cover" certain local and state learning standards. Pacing occurs based on the assessment calendar. Though inquiry-driven learning also aligns with learning standards, it requires flexibility and practice. To successfully mount the challenges that accompany a student-driven learning environment, teachers benefit from a collaborative team with the multi-faceted expertise to create interest and engagement while also responding to questions and challenges.

Chapter 4 included a description of how one water-quality lesson evolved from typical to inquiry-centered. The original lesson was clear and included the steps necessary to test water quality. In the revised version, though, the teacher reported students being more interested and engaged. They were creating maps of the area, utilizing skills that spanned multiple content areas. The question-driven nature of the revised lesson illustrates how they could ask and reflect rather than simply follow teacher-driven steps.

This example shows Tori's ability to make a water quality test part of a larger learning experience, one owned by students and tied to the local climate. Her related comments show that this approach is something she would not have undertaken ten years ago. Rather than "covering content," her modified approach shows the shift to studentdirected learning. Also noteworthy is the inclusion of literacy instruction in her science lesson. Tori regularly asks students to take part in notebooking activities (in this case, sketchnoting). Again we see the shift from "creating a lesson" to "adopting a place-based 
stance." The result is student-led learning that reinforces their science knowledge while strengthening their disciplinary literacy skills. What might have felt out of place to her in the science classroom five years ago is now part of her regular approach.

The path to facilitating student-led inquiry is slow and steady. Our leadership group learned that each situation calls for careful planning but alsoin-the-moment adaptation. With confidence in the rationale behind place-based pedagogy and comfort in the availability of expert support of colleagues, the team no longer feels that they must approach classroom instruction or professional development sessions with all variables known. A growing ease with the uncertainties of place-based instruction is evident in the team's responses and observable in their work.

This increased confidence extends to the students and is reflected in the placebased literature. As explored in Chapter 2, theories and literature of place-based pedagogy emphasize the development of students as both thinkers and responsible citizens (Clifton, 2017; Smith, 2002). In this study, this is shown through the experience Tori's students have with environmental issues like water quality and sustainable plantings. By taking ownership over their learning, her students explore meaning in ways not always supported in school (Austin, 2015; Brooke, 2003; Deringer, 2017; Sobel, 2013). Collaborative in nature, place-based pedagogy values disciplinary expertise while engaging students in inquiry-centered learning (Deringer, 2017; Elliott \& Jacobs, 2011). This group formed enduring partnerships by drawing on the expertise of educators, scientists, historians and business leaders. By utilizing the unique features of community, this approach encourages the development of critically thoughtful citizens (Demarest, 2015; Sobel, 2013). Lillian's belief in the importance of students coming to value 
community aligns with research on place-based pedagogy. To her, a place-based approach ties not only to her teaching, but also to her role as a mom and lifelong citizen.

Revisiting Figure 1 from Chapter 2, all implications from this study circle back to the idea that place-based pedagogy falls along a spectrum, contextualized in the surrounding environment of people, places, history and circumstances. Planning and control shifts away from being teacher centered; place-based educational environments evolve to become more collaborative and interdisciplinary, as inquiry fuels learning in an experience shared by students, teachers and community stakeholders.

\section{Figure 6}

\section{Continuum of Place-Based Pedagogy}

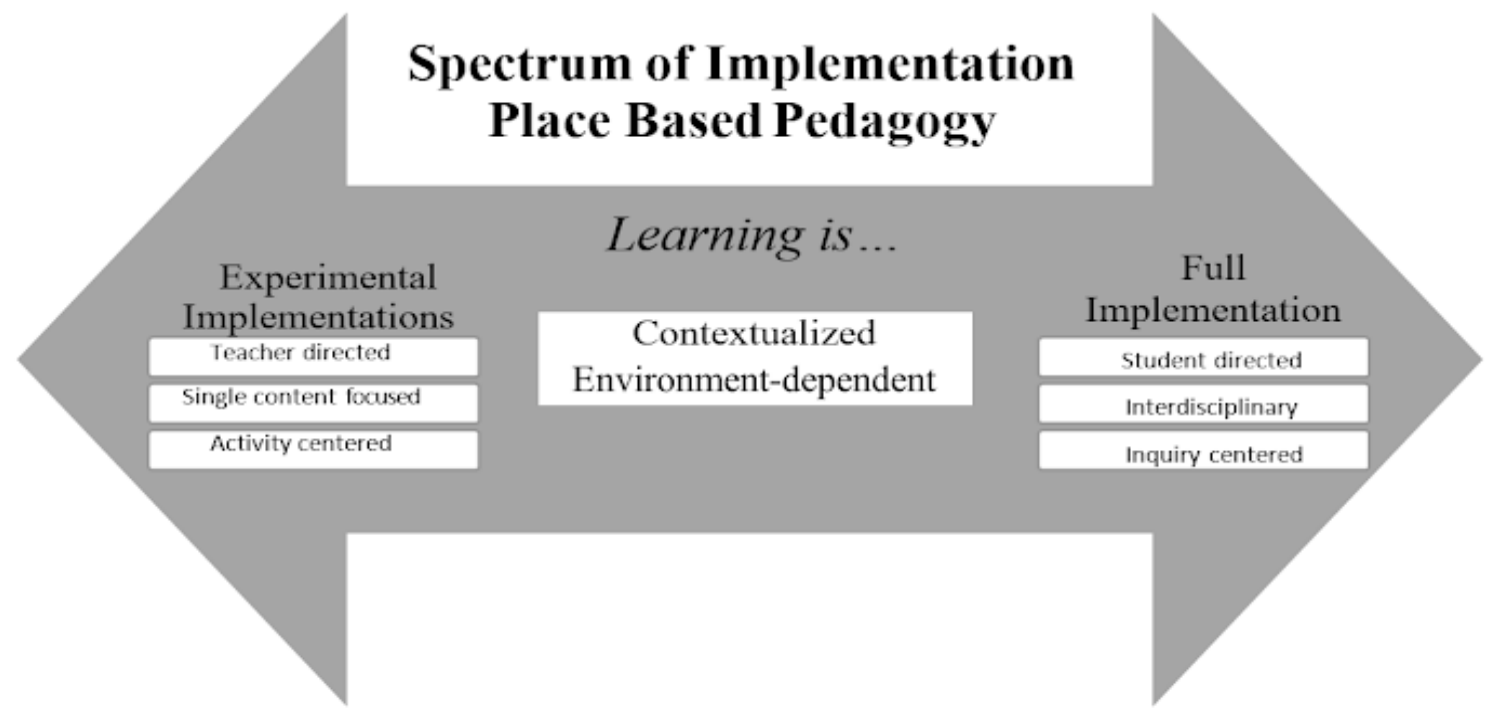

\section{Limitations}

As discussed in detail in Chapter 3, a number of limitations accompany this work, including the brief data-collection period and small group size of six, which may not fully reveal the nuances of teacher change. Biases, both in favor of and opposition to, the small 
town at the center of the work are sure to cloud participant responses. While design studies are not intended to be strictly replicated, the issue of transferability exists (i.e., how this professional development team will guide participants to replicate the activities apart from this very specific place). With regard to implementation, the complexities of learning (for both students and teachers) and human relationships (within and beyond school) make it impossible to specify all phenomena occurring in an instructional environment.

\section{Conclusion}

Teaching in a rural school can be an isolating experience. Most often in my career, I have been the only teacher instructing any given course. When challenges arise, talking with a colleague down the hall might not be as useful as in larger districts where course co-planning happens. Given that sense of seclusion, it is easy to feel further weighed down by changing learning standards. The data- and test-driven educational climate also affects teachers' sense of control over their learning environment. In current day classrooms, where views of teaching and learning often come charged with prescriptive, top-down expectations, the challenge to provide relevant, meaningful instruction can feel overwhelming. Because place-based practices can be added to existing curriculum, and because they can be implemented gradually, they work as a useful classroom tool.

Throughout my career, I have come to understand that quality professional development can combat feelings of isolation and provide professional support. Since first attending a Missouri Writing Project Invitational Summer Institute in 2004, I have valued this grassroots, sustained approach to professional development as career saving. 
Were it not for the value placed on teacher expertise, the built-in support system of likeminded colleagues, and the continual modeling of research-informed practice, I would not have lasted five years in a high school English classroom.

The interest in place-based pedagogy has been an exciting extension of my work as a teacher and professional development coordinator. Through this journey, our small leadership team has formed a lasting bond. Though colleagues prior to the start of the place-based work, we have come to know each other better professionally through our attempt to create a sustainable professional development model. We have generated and revised hands-on and reflective learning experiences. We have read professional texts, adapted materials to fit our circumstances, stepped back to ask what was working well and how we might improve. This project has been a meaningful exercise in sustained collaboration. Through the place-based professional development work, we have each emerged as more confident, capable and connected educators.

But the real question is what have we learned? Most notable is that we now understand the unique opportunity before us. While our small size and geographic isolation can be limiting, it also allows us to use our local area in unique ways. Each member of the team is connected to the community. Some of us have family who have lived in the area for generations. Others of us know (or are) business owners or local public leaders. Several of us own property or volunteer with organizations that offer access to people and spaces. While it might be easy to toss our hands up and say "we 
cannot," this group has willingly engaged in finding ways to say "we can."

To have a local museum supportive of our endeavor has been the fuel to this program's fire. The staff of the Museum has received our initiative with open arms. They have opened their space to us, offered singular expertise on local history, shared archival documents and historical artifacts. Without their partnership and access to resources, our unique program would not be possible. In considering next steps, our group will be seeking grant monies to fund future workshop experiences (moving from pilot phase to implementation phase). As subsequent workshops are implemented, the pool of leaders will then grow and draw upon a broader set of unique place experiences to expand and adapt the program in other locations.

Just as every member of the team brings unique personal connections, our diverse professional backgrounds also add value to the program. With expertise ranging across content areas and grade levels, we have come to understand and appreciate the variations in our day-to- day classroom environments. Collectively, our team instructs children in all grades K-12 across content areas. Building program leadership has included coming to understand the varied ways in which we interact with students. We each face unique challenges based on the age of our students and the content we instruct. Often, these struggles go unnoticed by colleagues. This leadership team now has a clearer picture of the daily demands colleagues face along with useful approaches to manage challenges. Ultimately what we have learned is that it is relationships that make programs 
thrive. We have found a way to solidify the support of community members in forming our school/community partnership. By drawing on the expertise of local scientists and historians, business owners and philanthropists, the place-based learning workshop offers a model of inquiry-driven, interdisciplinary collaboration. As a leadership team of educators in collaboration with a broader community-based support group, the placebased approach to learning leads to enduring habits and understanding. It doesn't just make the group better as teachers of their respective content, it makes them more community minded and participatory. A teacher as co-learner can design more effective instructional practices given the position to engage alongside students. As Percoco (2017) notes, "If you want a real professional learning community, get a bunch of like-minded, interested teachers and visit historic sites, go through archives...and let the conversation flow naturally" (p. 13). 


\section{Epilogue}

Place-based pedagogy is, in my mind, defined by the word "togetherness." The approach's collaborative underpinnings combine with immersive group learning experiences to mark the movement as collegial in nature. Yet I finish the writing of my dissertation in a world marked by stay-at-home orders and isolation. Thanks to the COVID-19 pandemic, school terms ended weeks early. Groups are not meeting, ceremonies and events have been canceled, many stores and restaurants are closed. Our world is experiencing mandated solitude.

Yet a closer look reveals that we are unified in a common experience. Across the globe, communities are experiencing similar fear and sadness. The uncertainties of the risks associated with exposure, the postponement or cancelation of graduation ceremonies and even memorial services. And while few if any would welcome a repeat of the events during the spring of 2020, perhaps there are lessons to be learned. Many have paused to spend time with family, to help in communities, to support one another as colleagues. Jobs were done in innovative ways as the use of digital tools like ZOOM and Google stretched to support professional and educational needs. When have humans felt a more shared experience?

The true impact of COVID-19 remains to be seen, as we are far from the end of this global crisis. And yet the implications for place-based pedagogy are worth considering as our team continues to plan and discuss the future of the place-based workshop. Can the experience on the flat-bed farm truck be adapted to reach learners bound by stricter physical confines? Will we learn to slow down and ponder our environment, whether together or alone? Can our team create digital versions of the 
workshop activities that provide a model for effective online instruction? Perhaps COVID-19 will add another layer of flexibility to this professional development model. 


\section{References}

Allen, J., \& Alexander, L. (Eds.) (2013). A critical inquiry framework for $k$-12 teachers: Lessons and resources from the U.N. Rights of the Child. Teachers College Press.

Alvermann, D. E., \& Moje, E. B. (2013). Adolescent literacy instruction and the discourse of "every teacher a teacher of reading." Theoretical models and processes of reading, 6, 1072-1103.

Austin, M. (2015). Reading the world: Ideas that matter. (3rd ed.). W.W. Norton \& Company.

Azano, A. (2011). The possibility of place: One teacher's use of place-based instruction for English students in rural high school. Journal of Research in Rural Education, 26(10), 1-12.

Barley, Z.A. \& Beesley, A.D. (2007). Rural schools: What can we learn? Journal of Research in Rural Education, 22(1), 1-16.

Beck, A. (2005). A place for critical literacy. Journal for Adolescent \& Adult Literacy, 48(5), 392-400. https://doi.org/10.1598/JAAL.48.5.3

Behrman, E. H. (2006). Teaching about language, power, and text: A review of classroom practices that support critical literacy. Journal of Adolescent \& Adult Literacy, 49(6), 490-498. https://doi.org/10.1598/JAAL.49.6.4

Bode, B. H. (1938). Progressive education at the crossroads. Newson \& Co.

Brandt, D., \& Clinton, K. (2002). Limits of the local: Explaining perspectives on literacy as a social practice. Journal of Literacy Research, 34(3), pp. 337-356. https://doi.org/10.1207/s15548430jlr3403_4

Brooke, R.E. (2003). Rural voices: Place-conscious education and the teaching of 
writing. Teachers College Press.

Buehl, D. (2014). Classroom strategies for interactive learning (4th ed.). International Reading Association.

Clifton, J. (2017). Argument as dialogue across difference: Engaging youth in public literacies. Routledge.

Cobb, P.M., Jackson, K.D., \& Dunlap, C.A. (2015). Design Research: An analysis and critique. In L. English \& D. Kirshner (Eds.), Handbook of international research in mathematics education (3rd ed.). (pp. 481-503). Routledge.

Darling-Hammond, L., Wei, R. C., Andree, A., Richardson, N., \& Orphanos, S. (2009). Professional learning in the learning profession. Washington, DC: National Staff Development Council, 12 .

Demarest, A.B. (2011). Place-based curriculum design: Exceeding standards through local investigations. Routledge.

Deringer, S.A. (2017). Mindful place-based education: Mapping the literature. Journal of Experiential Education, 40(4), 333-347. https://doi.org/10.1177/1053825917716694

Dewey, J. (1915/1966). Democracy and education: an introduction to the philosophy of education. The Free Press.

Dewey, J. (1938). Experience and education. Kappa Delta Pi.

Dobbs, C.L., Ippolito, J. \& Charner-Laird, M. (2017). Investigating disciplinary literacy: A framework for collaborative professional learning. Harvard Education Press.

Donehower, K., Hogg, C. \& Schell, E. E. (2007). Rural literacies. Southern Illinois University Press. 
Elliott, L. A., Jaxon, K., \& Salter, I. (2016). Composing science: A facilitator's guide to writing in the science classroom. Teachers College Press.

Ellis, A., \& Eberly, T. L. (2015). Critical literacy: Going beyond the demands of the Common Core. Illinois Reading Council Journal, 43(2), 9-15. http://www.illinoisreadingcouncil.org/publicationsservices/ircjournal.html

Fang, Z. (2012). The challenges of reading disciplinary text. In Jetton, T. L., \& Shanahan, C. (Eds.), Adolescent literacy in the academic disciplines: General principles \& practical strategies. The Guilford Press.

Fisher, D., \& Frey, N. (2014). Speaking \& listening in content area learning. The Reading Teacher, 68(1), 64-69. https://doi.org/10.1002/trtr.1296

Flower, L. (2008). Community literacy and the rhetoric of public engagement. Southern Illinois University Press.

Foucault, M. (1978). Discipline and punish: The birth of the prison. New York, NY: Pantheon.

Freire, P. (1983). Education for critical consciousness. Bloomsbury Revelations.

Garet, M. S., Porter, A. C., Desimone, L., Birman, B. F., \& Yoon, K. S. (2001). What makes professional development effective? Results from a national sample of teachers. American Educational Research Journal, 38(4), 915-945. https://doi.org/10.3102/00028312038004915

Gee, J.P. (2004). Situated Language and learning: A critique of traditional schooling. Routledge.

Gosselin, D., Brurian, S., Lutz, T., \& Maxon, J. (2016). Integrating geoscience into undergraduate education about environment, society, and sustainability using 
place-based learning: Three examples. Journal of Environmental Studies and Science, 6, 531-540. https://doi.org/10.1007/s13412-015-0238-8

Grossman, P., Hammerness, K., \& McDonald, M. (2009). Redefining teaching, reimagining teacher education. Teachers and Teaching: Theory and Practice, 15(2), 273-289. https://doi.org/10.1080/13540600902875340

Gruenewald, D. A. (2003). The best of both worlds: A critical pedagogy of place. Educational Researcher, 32(4), 3-12. https://doi.org/10.3102/0013189X032004003

Harlen, W. (2015). Teaching science for understanding in elementary and middle schools. Heinemann.

Heath, S.B. (1983). Ways with words: Language, life and work in communities and classrooms. Cambridge University Press.

Heath, S. B., \& Street, B. V. (2008). On Ethnography: Approaches to Language and Literacy Research. Teachers College Press.

Hill, A. E. (2014). Using interdisciplinary, project-based multimodal activities to facilitate literacy across the content areas. Journal of Adolescent Literacy, 57(6), 450-460. http://dx.doi.org/10.1002/jaal.270

Jacobs, E. (2011). Replace your typical writing assignment: An argument for place-based writing. The English Journal, 100(3), 49-54. https://www.jstor.org/stable/25790061

Jennings, N., Swidler, S., \& Koliba, C. (2005). Place-based education in the standardsbased reform era - Conflict or complement? American Journal of Education, 112(1), 44-65. https://www.jstor.org/stable/10.1086/444522 
Jetton, T. L., \& Shanahan, C. (Eds.). (2012). Adolescent literacy in the academic disciplines: General principles \& practical strategies. The Guilford Press.

Keengwe, J. (Ed.). (2017). Handbook of research on mobile technology, constructivism, and meaningful learning. IGI Global.

Leavy, P. (2017). Research design: Quantitative, qualitative, mixed methods, arts-based, and community-based participatory research approaches. Guilford Press.

Lee, C. (2011). Myths about critical literacy: What teachers need to unlearn. Journal of Language \& Literacy Education, 7(1), 95-102. http://www.coa.uga.edu/jolle/2011_1/lee.pdf

Lesh, B. (2011). "Why won't you just tell us the answer?": Teaching historical thinking in grades 7-12. Stenhouse Publishers.

Lesley, M.K. (2014). Policy, pedagogy, and research: Three issues affecting content area literacy courses for secondary-level teacher candidates. Reading Research and Instruction, 50, 50-71. https://doi.org/10.1080/19388071.2013.826761

Lewis, C., Encisco P., \& Moje, E.B. (2007). Reframing sociocultural research on literacy: Identity, agency, and power. Lawrence Erlbaum Associates.

Limmemanstons, K.A., \& Jordan, C.M. (2017). Learning through place: Evaluation of a professional development program for understanding the impact of place-based education and teacher continuing education needs. Journal of Sustainability Education, 12, 1-23. http://www.jsedimensions.org/wordpress/content/learningthrough-place-evaluation-of-a-professional-development-program-forunderstanding-the-impact-of-place-based-education-and-teacher-continuingeducation-needs_2017_02/ 
Marcus, A.S., Stoddard, J.D, Woodward, W.W. (2012). Teaching history with museums: Strategies for K-12 social studies. Routledge.

Marton, F., \& Booth, S. (1997). Learning and awareness. Lawrence Erlbaum Associates.

Merriam, S. B. (2009). Qualitative Research: A Guide to Design and Implementation. Jossey-Bass.

Moffett, J. (1983). Teaching the universe of discourse. Houghton Mifflin Company. Moffett, J. (1988). Storm in the mountains: A case study of censorship, conflict, and consciousness. Southern Illinois University Press.

Moje, E. B. (2015). Doing and teaching disciplinary literacy with adolescent learners: A social and cultural enterprise. Harvard Educational Review, 85(2), 254-278. https://doi.org/10.17763/0017-8055.85.2.254

Oncescu, J. \& Giles, A. (2014). Rebuilding a sense of community through reconnection: The impact of a rural school's closure on individuals without school-aged children. Journal of Rural and Community Development, 9(3), 295-318.

Papola-Ellis, A., \& Eberly, T. L. (2015). Critical literacy: Going beyond the demands of common core. Illinois Reading Council Journal, 43(2), 9-15. http://www.illinoisreadingcouncil.org/publicationsservices/ircjournal.html

Pearson, P. D., Moje, E., \& Greenleaf, C. (2010). Literacy and science: Each in the service of the other. Science, 328(5977), 459-

463. https://doi.org/10.1126/science.1182595

Penney, D. (2013). Points of tension and possibility: boundaries in and of physical education, Sport, Education and Society, 18(1), 6-20.

https://hdl.handle.net/10289/7084 
Percoco, J.A. (2017). Take the journey: Teaching American history through place-based learning. Steinhouse.

Perry, K. H. (2012). What is literacy? -- A critical overview of sociocultural perspectives. Journal of Language and Literacy Education, 8(1), 50-71. http://jolle.coe.uga.edu/wp-content/uploads/2012/06/What-is-Literacy_KPerry.pdf

Powers, A. L. (2004). An evaluation of four place-based education programs. The Journal of Environmental Education, 35(4), 17-32. https://doi.org/10.3200/JOEE.35.4.17-32

Pratt, C., Frazier, I., Turley, K., \& Semel, S. F. (2014). I learn from children: An adventure in progressive education. Grove Press.

Quinn, N. (Ed.). (2016). Finding culture in talk: A collection of methods. Springer.

Reid, W.A. (2006). The pursuit of curriculum: Schooling and the public interest (2nd ed.). Information Age Publishing.

Reinking, D., \& Bradley, B.A. (2008). On formative and design experiments: Approaches to language and literacy research. Teachers College Press.

Schmoker, M. (2011). Focus: Elevating the essentials to radically improve student learning. ASCD.

Seidman, I. (2006). Interviewing as qualitative research: A guide for researchers in education and the social sciences. Teachers College Press.

Selwyn, D. (2010). Following the threads: Bringing inquiry research into the classroom. Peter Lang.

Semken, S., Ward, E. G., Moosavi, S., \& Chinn, P.W.U. (2017). Place-based education in geoscience: Theory, research, practice and assessment, Journal of Geoscience 
Education, 65, 542-562. https://doi.org/10.5408/17-276.1

Shanahan, T., \& Shanahan, C. (2008). Teaching disciplinary literacy to adolescents: Rethinking content-area literacy. Harvard Education Review, 78(1), 40-59. https://doi.org/10.17763/haer.78.1.v62444321p602101

Smith, G. A. (2002). Place-Based Education: Learning to Be Where We are. Phi Delta Kappan, 83(8), 584-594. https://doi.org/10.1177/003172170208300806

Sobel, D. (2013). Place-based education: Connection classrooms and communities. (2nd edition). Orion.

Stack, S.F. (2016). The Arthurdale community school: Education and reform in Depression era Appalachia. The University Press of Kentucky.

Street, B.V. (1984). Literacy in theory and practice. Cambridge University Press.

Tan, Y.S.M., \& Atencio, M. (2016). Unpacking a place-based approach -- "what lies beyond?" insights drawn from teachers' perceptions of outdoor education. Teaching and Teacher Education, 56, 25-34. https://doi.org/10.1016/j.tate.2016.02.001

Tyson, L.M., Venville, G.J., Harrison, A.G., \& Treagust, D.F. (1997). A multidimensional framework for interpreting conceptual change events in the classroom. Science Education, 81, 387-404. https://doi.org/10.1002/(SICI)1098237X (199707) 81:4<387::AID-SCE2>3.0.CO;2-8

United Nations Educational, Scientific, \& Cultural Organization. (2005). Education for All Global Monitoring Report. UNESCO.

Vygotsky, L. S. (1978). Mind in society: The development of higher psychological processes. Harvard University Press. 
Vygotsky, L.S. (1986). Thought and Language. MIT Press.

Washburne, C. (1952). What is progressive education?: A book for parents and others. J. Day Co.

Wenner, J. A., \& Campbell, T. (2017). The theoretical and empirical basis of teacher leadership: A review of the literature. Review of educational research, 87(1), 134171. https://doi.org/10.3102/0034654316653478

Wilhelm, J.D. \& Novak, B. (2011). Teaching literacy for love and wisdom: Being the book and being the change. Teachers College Press.

Wodak, R., \& Meyer, M. (Eds.). (2015). Methods of critical discourse studies. Sage. 


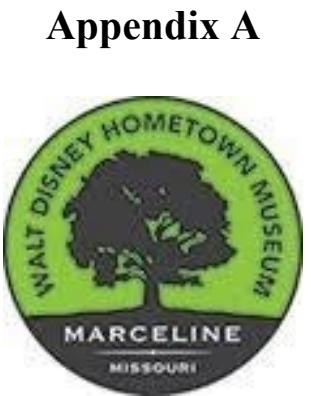

\section{Place-Based Education Initiative Daily Schedule}

\section{DAY 1}

(Purpose is to establish interest and provide context of both "the place" and the project.)

Key Activities:

Classroom orientation; Small group guided "breakout activity" in main museum building; Museum guided tour (of all main building exhibits); Time in Museum classroom for questions, debriefing, and structured writing time. The room arrangement will allow facilitation team members to be interspersed with participants so that discussions can easily flow from small to whole-group configuration. (Participants will have received copies of selected readings and some orientation materials in advance of day 1.)

\section{DAY 2}

(Purpose is to consider content and grade-level ties through the study of artifact, as well as application of concepts to participants' local features.)

Key Activities:

Using the History of Railroading and Coal Mining displays (in secondary building, "The Beanery") to study social issues. Considering how place-based learning fits into social studies classrooms. A deep study of artifact will include the following treasures:

- Multiple uniforms used during by railroad employees (working in different roles)

- A complete "grip" (or work bag) used by a local railroader and lifelong resident

- Unpublished photographs detailing the laying of the track and the construction of the original overhead bridge (including wooden bricks saved from its demolition)

The careful study of artifact will afford participants an opportunity to consider daily success and struggle and compare it to the issues of today.

Lunch on day 2 will model the importance of drawing on local expertise by inviting a local railroad historian (and former BNSF employee) to speak on local railroad history.

\section{DAY 3}

(Purpose is to model how place engages with content area and grade level.)

What we can learn about our natural environment (and the study of science) from visiting area farms. As detailed in the narrative, the Day 3 schedule will provide opportunity to consider more directly how physical location impacts learning. The science teachers on the facilitation team will guide participants in studying how science connects to broader study (and critical thinking) through activities such as science notebooking, visual notetaking, and exploring water quality. While the water quality activity looks like a tpyical science experiment in many ways, its position amid preview and follow-up activities will demonstrate one meaningful way to expand the walls of the classroom and think of the how science connects to citizenship.

\section{DAY 4 (Follow-up Regroup)}

(Purpose is to continue classroom planning and sharing of professional resources.)

Participants will spend time engaged with Mapping Your Place Tree Model activity supporting teachers in classroom planning (creation of concept maps tied to local place); Discussion of core readings; Participants will share model lessons (and share highlights of classroom application that include photo, video and student work). 


\section{Appendix B}

\section{Place-Based Education Initiative Lesson Review Protocol}

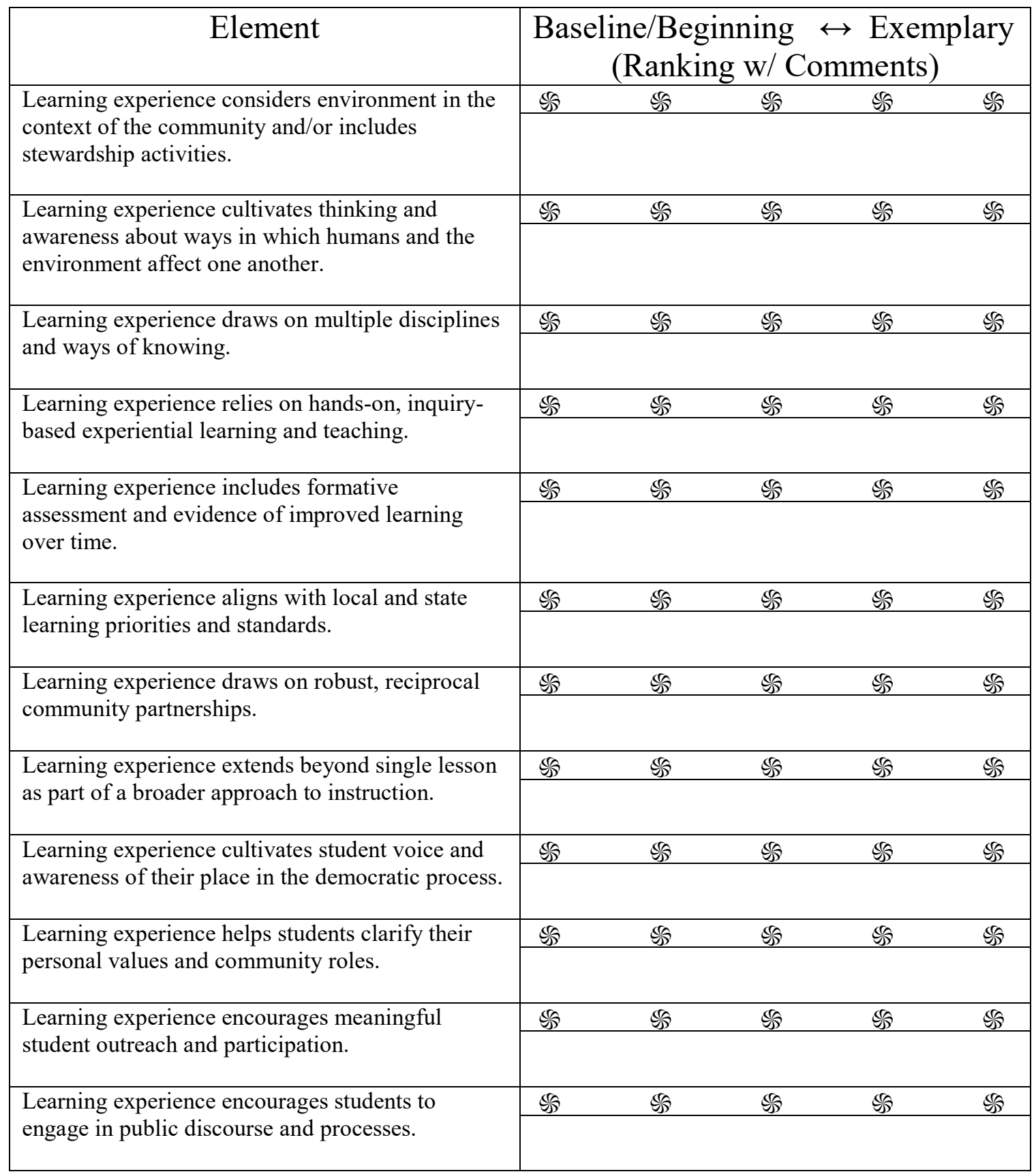




\section{Appendix C}

\section{IRB Consent Form}

\section{MU Campus Institutional Review Board Consent Form for Research Study}

\section{Project Title}

The Impact of Place-Based Pedagogy on Teachers' Professional Identities, Instructional Decisions, and Collaborations

\section{Purpose of the Study}

You have been asked to take part in a study that explores teachers' understanding and use of place while implementing instruction and collaboratively building a professional development experience for colleagues. You will be among a team of classroom teachers possessing a range of professional experience in using a place-based, collaborative approach.

\section{What am I going to be asked to do?}

If you agree to take part in this study, the research team will:

$\square \quad$ Conduct three informal, semi-structured interview, lasting approximately 45-60 minutes.

$\square \quad$ Collect and short self-reflections that are part of your regular instruction.

$\square \quad$ Collect relevant documents you create during your instruction (including drafts, sketches, notes, finished products) that show your place-based pedagogical decisions.

$\square \quad$ Participate in a final, group interview of approximately 60 minutes. This will be video recorded.

$\square \quad$ Appearance in photos that will enhance clarity about the project.

\section{Length of Study}

This study will take place primarily during the Fall 2019 semester. Data collection will end no later than May 31, 2020

\section{Who do I contact if I have questions, concerns, or complaints?}

Please contact Julie Sheerman or Dr. Amy Lannin if you have questions about the research.

Julie Sheerman

(660) 413-2248

sheerman@mail.missouri.edu

LanninA@missouri.edu
Dr. Amy Lannin

(573) 882-1798

I understand that my participation in this research is completely voluntary, and I can terminate my participation at any point. 


\section{Appendix D}

\section{IRB Approval}

Institutional Review Board University of

Missouri-Columbia FWA Number: 0002876

IRB Registration Numbers: 00000731,00009014
482 McReynolds Hall

Columbia, MO 65211

573-882-3181

irb@missouri.edu

October 02, 2019

Principal Investigator: Julie M. Sheerman (MU-Student) Department:

Learn, Teach and Curric - PHD

Your IRB Application to project entitled The Impact of Place-Based Pedagogy on Teachers' Professional Identities, Instructional Decisions, and Collaborations was reviewed and approved by the MU Institutional Review Board according to the terms and conditions described below:

$\begin{array}{ll}\text { IRB Project Number } & 2017505 \\ \text { IRB Review Number } & 254240 \\ \text { Initial ApplicationApproval Date } & \text { October 02,2019 } \\ \text { IRB Expiration Date } & \text { October 02,2020 } \\ \text { Level of Review } & \text { Exempt } \\ \text { Project Status } & \text { Active - Exempt } \\ \text { ExemptCategories(Revised Common Rule) } & 45 \text { CFR 46.104d(2) } \\ \text { Risk Level } & \text { Minimal Risk }\end{array}$

The principal investigator (PI) is responsible for all aspects and conduct of this study. The PI must comply with the following conditions of the approval:

1. No subjects may be involved in any study procedure prior to the IRB approval date or after the expiration date.

2. All changes must be IRB approved prior to implementation utilizing the Exempt Amendment Form.

3. The Annual Exempt Form must be submitted to the IRB for review and approval at least 30 days prior to the project expiration date to keep the study active or to close it.

4. Maintain all research records for a period of seven years from the project completion date.

If you are offering subject payments and would like more information about research participant payments, please click here to view the MU Business Policy and Procedure: http://bppm.missouri.edu/chapter2/2 250.html

If you have any questions or concerns, please contact the MU IRB Office at 573-882-3181 or email to muresearchirb@missouri.edu.

Thank you,

MU Institutional Review Board 


\section{Vita}

Julie Sheerman will, COVID pending, enter her high school classroom for the twenty-second year this August to instruct senior composition. Each class of high school seniors reminds her of the potential in young learners - and not to take anything in life too seriously. In addition to this part-time contract, she works with other National Writing Project Teacher Consultants to organize professional development projects for the Missouri Writing Project and the Missouri Writing Projects Network. She feels fortunate to keep one foot in the classroom while engaging with teachers in a number of professional learning initiatives.

Of particular interest to Julie is work at the center of this study, place-based pedagogy. She has also dedicated many professional hours to participating in largescale writing assessment hosted by the National Writing Project. Several opportunities in recent years have offered the challenge to explore disciplinary literacy with talented ELA and content teachers. She feels fortunate to be part of the blend of student and colleague expertise. 